\title{
Positivismo jurídico, Estado de Derecho y libertad: una propuesta de formulación Legal Positivism, Rule of Law and Freedom: A Proposal for Formulating
}

\author{
Tomás A. Arias Castillo \\ Universidad Central de Venezuela \\ ariascastillo@gmail.com \\ Luis Alfonso Herrera Orellana \\ Universidad Central de Venezuela \\ laho76@gmail.com
}

Recibido / received: 30/07/2018

Aceptado / accepted: 01/02/2019

DOI: https://doi.org/10.20318/eunomia.2019.4692

\section{Resumen}

En el presente trabajo se exploran las posibles vías de conexión entre el positivismo jurídico, el liberalismo clásico y el Estado de Derecho, tarea que siempre se ha visto dificultada por la visión antipositivista de los autores liberales. En tal sentido, se analizan y responden las críticas antipositivistas con el propósito de mostrar la compatibilidad entre el positivismo jurídico y el ideal del Estado de Derecho.

\section{Palabras clave}

Liberalismo clásico, positivismo jurídico, Estado de Derecho, separación entre derecho y moral, fuentes sociales del derecho.

\section{Abstract}

This article explores possible connections between legal positivism, classical liberalism and the rule of law, a task that has been obstructed by the anti-positivist vision of liberal authors. In that sense, anti-positivists critics are analyzed and contested with the purpose of showing the compatibility between legal positivism and the rule of law ideal.

\section{Keywords}

Classical liberalism, legal positivism, rule of law, separation between law and morals, social sources of the law. 


\begin{abstract}
SUMARIO. 1. Introducción. 2. El positivismo jurídico, o una caricatura deformante. 3. Las tesis fuertes del positivismo jurídico y, en especial, su acoplamiento con el ideal regulativo del Estado de Derecho. 3.1. La separación conceptual entre derecho y moral. 3.2. La tesis de las fuentes sociales del derecho. 4. Una caracterización de las críticas contemporáneas más notorias al positivismo jurídico. 5 . ¿Se sostiene la crítica liberal al positivismo jurídico? 6. Las amenazas actuales al Estado de Derecho y, por ende, a la libertad individual. 7. Algunas conclusiones.
\end{abstract}

\section{Introducción}

Desde que les descubrimos hace ya algunos años, llamaron nuestra atención el liberalismo clásico y el positivismo jurídico. El primero era un perfecto desconocido en los tiempos de nuestros estudios universitarios, ya que las doctrinas en defensa de la libertad política y de la libertad económica -sobre todo de ésta última- eran olímpicamente silenciadas, cuando no tratadas con abierto irrespeto. Las universidades y los centros de enseñanza, en general, no suelen ser muy receptivos con la doctrina liberal. En cuanto al positivismo jurídico, el asunto es más complicado, porque sí recibimos un entrenamiento profesional sobre el derecho positivo, sí empleamos el utillaje conceptual de la teoría general del derecho (contentiva de las generalizaciones derivadas de la forma positivista de acercarse al derecho), pero fuimos persistentemente confundidos sobre lo que el positivismo jurídico significaba. Eso, sin uno quererlo, puede ir generándole una relación amor-odio hacia el positivismo. Y, luego, para colmo de males, cuando estudiamos a los autores liberales contemporáneos, nos dimos cuenta de que ellos eran, casi en su totalidad, antipositivistas. Parecía que, en el ámbito jurídico, no se podía ser las dos cosas a la vez, liberal y positivista, para nuestro pesar.

Muchas lecturas después, notamos que en las posiciones antipositivistas incluida la posición liberal predominante- había una serie de prejuicios, errores y falsedades que mostraban una versión distorsionada sobre el positivismo jurídico y que, entonces, era necesario conocer a fondo, y de la pluma de los propios autores positivistas, las tesis centrales de dicha corriente del pensamiento legal. Luego de cumplir tal tarea, llegamos a la conclusión de que dichas tesis centrales en nada contradicen al pensamiento liberal y, peor aún, que el liberalismo se había negado durante décadas a dar recepción a la mejor explicación sobre el surgimiento y funcionamiento del derecho, sin contar con buenas razones para ello.

Entonces, surgió la idea de empezar a trabajar la posible vinculación del positivismo jurídico con el liberalismo político y económico (Arias Castillo, 2013; Herrera Orellana, 2013), de lo cual es muestra el presente trabajo, en el que se quiere evidenciar ese trayecto de "poner al positivismo jurídico en su justo lugar", para luego mostrar que hay plena compatibilidad entre aquel y la defensa de una sociedad conformada por individuos libres.

Como anunciamos en el título, nuestro plan es ir enriqueciendo esta propuesta de acercamiento entre positivismo y liberalismo, la cual encontramos útil y fructífera para, por una parte, realizar hacer una clara descripción de los sistemas jurídicos y, 
por otra parte, defender mejor un sistema de ideas que aguarda todavía por contar con una teoría jurídica consistente ${ }^{1}$.

\section{El positivismo jurídico, o una caricatura deformante}

Un primer asunto que debe analizarse de manera concienzuda cuando hablamos sobre este tema es cuánta verdad hay en el común aserto según el cual el positivismo es una teoría desvinculada de los valores y principios (contenidos morales) propios de las democracias constitucionales, así como que tiende a justificar "cualquier" régimen político y, por ende, a colaborar en una especie de ideología justificadora del poder contra el individuo ${ }^{2}$.

En ese sentido, vemos que el positivismo jurídico sigue siendo el blanco de las más obstinadas reticencias, así como de los mayores desplantes y ataques, a pesar de su coherente desarrollo teórico y conceptual (mucho mayor que el de cualquiera de sus teorías rivales contemporáneas), y no obstante haber contestado y aclarado las objeciones a las cuales ha sido sometido a través de décadas ${ }^{3}$.

Esta actitud antipositivista se ha convertido en una especie de ideología en lo atinente a la materia jurídica y suele agrupar creencias y corrientes aparentemente irreconciliables entre sí, desde el laissez faire hasta el colectivismo comunista y desde el conservadurismo religioso y moral hasta el progresismo en materia social y cultural, lo cual ya haría sospechar a más de uno. Los liberales, por un lado, acusan el exceso de estatismo, dirigismo y de autoritarismo ${ }^{4}$, mientras que los colectivistas ven lo contrario: una defensa del status quo $0^{5}$, una falta de vinculación con el origen de las relaciones sociales (Paŝukanis: 1976: 29) y un obstáculo al cambio ${ }^{6}$. Los conservadores ven un ataque a los principios y valores tradicionales presentes en la moral y en las buenas costumbres ${ }^{7}$, mientras que los progresistas ven actitudes demasiado conservadoras, falta de flexibilidad y de adaptación al entorno siempre cambiante $^{8}$. Todos tienen una versión del positivismo adaptada a sus pretensiones en el campo político, social y económico o, incluso al terreno ya de los intereses personales o de grupo.

El colmo de esta postura antipositivista, sin duda, se produjo en la Alemania del nacionalsocialismo. Antes de la segunda guerra mundial los nazis estigmatizaron al positivismo jurídico por su carácter individualista y por su defensa "extrema" de la seguridad jurídica, que resultaba contraria al "espíritu de comunidad" que debía supuestamente imperar en el pensamiento alemán. Además, persiguieron a los autores positivistas -especialmente si eran judíos- despojándolos de sus cátedras universitarias y prohibiendo y quemando sus libros. Aun así, después de la segunda guerra mundial, esos mismos nazis, acusados por delitos de guerra y delitos contra la humanidad, invocaron la obediencia debida y, temerariamente, adujeron la excesiva influencia del positivismo jurídico como determinante en la cultura jurídica antes y durante el conflicto bélico, todo lo cual les hacía cumplir ciegamente las

\footnotetext{
${ }^{1}$ Además somos conscientes de que, en los últimos dos siglos, los paradigmas del positivismo jurídico y del liberalismo político y económico, han tenido situaciones de acercamiento, coincidencias parciales, así como distanciamientos, siendo esto último lo que se verifica normalmente hoy en día.

2 Un ejemplo de dicha visión: Atienza Rodríguez y Ruiz Manero (2007).

${ }^{3}$ Cfr. Hoerster (2000: 9 y ss.). Como ejemplos de contestación a los críticos: Coleman (2005) y Kramer, Grant, Colburn y Hatzistavrou (2012).

${ }^{4}$ Herrán Alonso (2010: 191 y ss.).

5 Ver Stučka (1974: 63-96) y Cerroni (1976: 47).

${ }^{6}$ Ver Novoa Monreal (1981: 38 y ss.) y Atienza Rodríguez (2017: 345-361).

${ }^{7}$ Como Lord Devlin en su disputa con H.L.A. Hart, en la década de 1960, en torno a la penalización de la homosexualidad y la prostitución. Cfr. Hart (2006).

${ }^{8}$ A manera de ejemplo: Dworkin (2007). Un comentario a dicho trabajo en Arias Castillo (2007).
} 
instrucciones que recibían. Muy difícilmente puede creerse o construirse un relato así, basado en la mentira desnuda. Sin embargo, desde entonces existe ya toda una doctrina, una especie de neo-iusnaturalismo o iusmoralismo ${ }^{9}$, que ataca al positivismo jurídico por incentivar conductas como las seguidas por los agentes del nazismo ${ }^{10}$.

Lo que claramente ha ocurrido con el positivismo jurídico, en la postguerra sobre todo, es la puesta en práctica de una obvia estrategia de descrédito basada en una caricatura deformante o, lo que es lo mismo, una apelación a la famosa falacia del hombre de paja, la cual, como señala Tindale (2007: 19-28), es una falacia de distracción (nos hace atacar la posición de un "hombre de paja" especialmente fabricado, en vez de refutar la posición del "hombre real"), que es muy sensible al contexto en el cual se producen los señalamientos falaces. En el caso específico del positivismo jurídico, fue empleado como chivo expiatorio tanto por los nazis para justificar sus crímenes, como por quienes los juzgaron y condenaron desde posiciones iusmoralistas, para negar cualquier carácter jurídico al derecho del Tercer Reich. Todo ello brindó -si bien de forma injustificada y falaz- un contexto de descrédito ${ }^{11}$.

Al clima intelectual, político y de opinión pública de la postguerra, se suma además el señalado hecho de las distintas ideologías en pugna y que tradicionalmente achacan al positivismo jurídico lo que, en verdad, son problemas, retos o incluso defectos (según se los vea) de los sistemas jurídicos. Si la justicia es "lenta", eso se debe a las rigurosidades del formalismo o ritualismo, que vendría a ser también una manifestación del positivismo jurídico, por sus escrúpulos hacia las normas escritas. Si la legislación invade más el terreno de la libertad económica, de la propiedad privada o de la libertad contractual, es porque aceptamos como "derecho" al derecho positivo, lo cual incluye las regulaciones contenidas en la Legislación y otros actos dictados en ejecución de aquella. Si la jurisprudencia "se estanca", no "avanza" en el sentido que queremos, o el derecho judicial no es lo suficientemente "realista", pretoriano, equitativo, o no aplica las herramientas del análisis económico y la teoría neoclásica de los precios de mercado ${ }^{12}$, es porque los jueces actúan como "autómatas", un rasgo, se aduce, del positivismo jurídico.

Luego, por supuesto, está Hans Kelsen, posiblemente el autor más cómodamente tergiversable de la filosofía y la teoría del derecho. Leído y discutido debidamente, uno puede criticar a un autor y su obra, más aún si lo es de la importancia y seriedad de Kelsen, quien además abordó una enorme cantidad de temas polémicos y publicó una valiente y extensa obra escrita ${ }^{13}$. Pero el tema es que decir "Kelsen", "kelseniano" o -peor- decir "positivismo kelseniano" pareciese dar licencia para denostar a todo aquello que nos resulta insatisfactorio sobre los sistemas jurídicos, en el sentido antes apuntado, sin que siquiera importe traer una prueba

\footnotetext{
${ }^{9}$ El término iusmoralismo, que empleamos a lo largo de este trabajo, lo hemos tomado de la obra del profesor García Amado (2015), quien con dicho término caracteriza a las doctrinas anti-positivistas contemporáneas cuyas posiciones sostienen que: (i) la moral es el elemento esencial y constitutivo de todo auténtico sistema jurídico; (ii) hay una parte de todo auténtico sistema jurídico que no proviene de acuerdos o convenciones sociales, sino de verdades morales; y (iii) existen métodos, procedimientos, para conocer el contenido de dichos preceptos provenientes de la moral. Como bien aclara García Amado (2015: 7-8), si bien no todo iusmoralismo necesariamente es iusnaturalista, todo iusnaturalismo, por fuerza, es iusmoralista.

10 Sobre las doctrinas jurídicas imperantes bajo el nacionalsocialismo (entre las cuales, por supuesto, no se encuentra el positivismo jurídico), ver Rüthers (2016: 51-119).

${ }^{11}$ Al respecto, ver García Amado (2010: 385-441). Sobre cómo Gustav Radbruch pasó a convertirse en un autor antipositivista en la postguerra, ver Hart (1962: 42-49).

12 Cfr. Posner (2016: 302-303).

13 Por solo ilustrar nuestra afirmación, nos remitimos a dos notorias disputas que tuvo Kelsen: la disputa con Schmitt sobre quién debía ejercer el control de constitucionalidad, y la sostenida con Smend sobre el Estado como integración. Cfr. Kelsen (2002b) y Kelsen (1997).
} 
cierta de lo supuestamente afirmado por el autor. Como bien lo apunta García Amado (2010: 415-421) en un ensayo cuyo título deja patente lo que aquí afirmamos, las tres mayores falsedades -no las únicas- sobre la obra de Hans Kelsen son las siguientes: (i) su teoría de la interpretación y la aplicación del derecho nos retrotraería a la decimonónica escuela de la exégesis, o la jurisprudencia de conceptos, convirtiendo al juez en un autómata, capaz apenas de subsumir unos hechos bajo una disposición normativa, bajo la forma de un silogismo; (ii) propugnaría la obediencia judicial y ciudadana al derecho injusto, donde se confundiría la obligación jurídica con la obligación moral, todo bajo un claro positivismo ideológico; y (iii) serviría como justificación para el autoritarismo estatal, como se habría demostrado de manera patente bajo el nacionalsocialismo.

Todo esto, que es falso para el caso de Kelsen ${ }^{14}$, también lo es para el positivismo jurídico en general, cuya quintaesencia, como veremos en el apartado siguiente, es la defensa de dos tesis centrales que lo diferencian de sus concepciones jurídicas rivales: (i) la separación conceptual entre derecho y moral; y (ii) las fuentes sociales, o convencionales, del derecho. Nada hay sobre una pretendida "aplicación mecánica de las leyes" ${ }^{15}$, ni acerca del supuesto deber de obediencia a las leyes injustas, o una defensa del autoritarismo estatal, en el modo analítico, utilitarista o positivista de acercarse al derecho, o en el positivismo jurídico como teoría. Y muy poco útil, por no decir irrelevante y casi inexistente desde el punto de vista de la literatura jurídica resulta el positivismo ideológico, o formalismo ético ${ }^{16}$, esto es, la defensa ideológica de las leyes positivas. Por eso insistimos: todo este antipositivismo se reduce a una caricatura deformante que es útil desmontar, por el bien de nuestra disciplina, para valorar -o de ser el caso, refutar- el positivismo por las tesis que verdaderamente defiende y no por algo distinto.

3. Las tesis fuertes del positivismo jurídico y, en especial, su acoplamiento con el ideal regulativo del Estado de Derecho

En segundo lugar, nos centraremos en las dos tesis fuertes del positivismo, que son tesis característicamente analíticas: (i) la separación conceptual entre derecho y moral; y (ii) las fuentes sociales del derecho. Dichas tesis son analíticas, además del hecho de partir de la denominada perspectiva externa del derecho, porque tienden a la clarificación conceptual. Y dicha clarificación conceptual es buena tanto para la práctica de una disciplina como para la creación científica sobre dicha disciplina, todo lo cual redunda en beneficio de la libertad. El derecho es un instrumento de la sociedad así como una práctica guiada por reglas. Son los miembros de la sociedad -y no la razón o la naturaleza de las cosas- quienes van confeccionando y afinando dicho instrumento y dicha práctica. Nadie dice que en la elaboración, interpretación, aplicación y enseñanza del derecho no tengan influencia elementos de tipo moral, político, económico, histórico, etc., pero aun así es posible separar dichos elementos cuando -de nuevo, desde la perspectiva externa- describimos problemas legales o

\footnotetext{
14 Un excelente capítulo dedicado a la vida y obra de Kelsen, donde pueden verse sus avatares como profesor y teórico en la República de Weimar, donde se destacó además como defensor del sistema democrático y de libertades, así como su caso de víctima de la persecución antisemita y antipositivista, en Sosa Wagner (2005: 379-420).

${ }^{15}$ Hart (1962: 30): "Los villanos de la pieza, responsables de la concepción de que el juez es un autómata, no son los pensadores utilitaristas. La responsabilidad, si debe recaer en algún teorizador, le corresponde más bien a pensadores como Blackstone y, en una época anterior, Montesquieu. La raíz de este mal es la preocupación por la separación de poderes y la 'infantil ficción' de Blackstone -así la llamaba Austinde que los jueces sólo 'declaran' y nunca 'crean' Derecho”.

${ }^{16}$ La distinción ya clásica entre positivismo como approach, como teoría y como ideología pertenece a Bobbio (2015: 101-122), quien señaló que lo verdaderamente valioso del positivismo jurídico era su distinción entre el derecho "que es" y el derecho "que debe ser", así como la tesis de las fuentes sociales del Derecho.
} 
normas jurídicas. Cosa distinta ocurre cuando evaluamos o criticamos el derecho aplicable, o cuando formulamos recomendaciones para su modificación, a partir de ideales morales, políticos o económicos. Describir, prescribir y evaluar son cosas diferentes. Ahí está el foco metodológico del positivismo.

\subsection{La separación conceptual entre derecho y moral}

En cuanto a la relación entre derecho y moral, es difícil, por no decir imposible, llegar a comprender y explicar la estructura y funcionamiento de un sistema jurídico si respecto de él se asume de entrada una perspectiva valorativa y un punto de vista exclusivamente interno restringido solo a la verificación de la correspondencia o no del mismo con un conjunto determinado de valores, en lugar de asumir más bien una perspectiva analítica y un punto de vista externo ${ }^{17}$, en el cual a partir de conductas observables en cualquier sistema jurídico se verifique, más allá de las piezas o componentes que lo integran, el grado de adhesión y cumplimiento (no por razones morales exclusivamente, sino debido a otros incentivos) de sus prescripciones, por parte de quienes actúan dentro de él, tal y como lo propuso H. L.A. Hart (2012: 110 y ss.) en El Concepto de Derecho ${ }^{18}$.

En efecto, mientras la perspectiva axiológica hace depender la validez, y en casos hasta la existencia, de una norma, una institución o una práctica social, de su correspondencia o grado de realización de un determinado valor, principio o marco teórico; la perspectiva analítica y externa deja de lado esa exigencia, no por inmoral o amoral, sino por coherencia con su propósito, que es conocer y no juzgar. Y, a partir de conceptos y definiciones generadas a partir de lo observado, describir la norma, institución o práctica social, afirmando su existencia y validez a partir del grado de reconocimiento, uso y aceptación manifestado en los usuarios o destinatarios de aquéllas, en atención a su pertenencia al sistema jurídico.

No evalúa, por tanto, el grado de justicia de la práctica social estudiada, sino que describe la conducta de los sujetos vinculados o involucrados con esa práctica, con fines muy concretos cabe señalar, más allá del reconocimiento de validez y vigencia, tales como su eficacia, utilidad, prevención de sanciones o generación de beneficios, efectos sobre terceros y las autoridades, etc.

Se puede afirmar que la perspectiva analítica fue asumida por Ludwig von Mises al describir el funcionamiento de la planificación centralizada en su obra Socialismo (Von Mises, 1999), para explicar, sin juzgar moralmente, el funcionamiento de dicho sistema económico. A partir de conceptos y definiciones aplicables a cualquier economía, considerando que toda economía responde al mismo problema humano -la escasez-, Mises se tomó en serio a la planificación central, a pesar de su rechazo a la misma, describió y explicó su desempeño, con el objeto de demostrar

\footnotetext{
17 Sobre el tema, véase Millaleo Hernández (2014: 143 y ss.).

18 Al respecto, Perry (2001: 320) expone: "The most straightforward understanding of methodological positivism would look to what I earlier called the descriptive-explanatory method. Legal theory is, on this view, a form of scientific enterprise the point of which is to advance, from an external viewpoint, descriptive, morally neutral theories of the social world. A particular theory adopts the characterization of empirical phenomena that it does because the theory's proponents believe that characterization has explanatory power. As was noted in the preceding section, explanatory power is most plausibly understood as referring to metatheoretical criteria for assessing scientific theories: predictive power, theoretical simplicity, and so on. On the descriptive-explanatory interpretation of Hart's methodology, the reason for equating 'law' (understood now as a term of art internal to the theory) with social systems based on a rule of recognition would be that one has grounds for believing that such a characterization has explanatory power in the sense just described".
} 
en qué medida dicho sistema resultaba contradictorio, ineficaz y poco observado, en la práctica, por sus destinatarios.

Si el autor citado, en lugar de lo anterior hubiera asumido una perspectiva axiológica del sistema económico, haciendo depender la existencia de este último de su correspondencia o grado de realización de los valores, normas y prácticas sociales de la economía de mercado, no hubiese podido escribir la referida obra, pues simplemente habría dicho que como la planificación central no se ajusta a la axiología económica que él considera válida, aquella entonces no es un sistema económico, conclusión que poco o nada habría permitido a los interesados conocer en qué medida la planificación resuelve o no el problema de la escasez.

Lo mismo ocurriría si, respecto de un sistema jurídico cuyo contenido y funcionamiento se quisiera conocer, en lugar de describirlo de entrada se lo pretendiera evaluar en cuanto a su adecuación o no a valores trascendentes o inmanentes al sistema, como los defendidos por los iusmoralismos en sus diversas manifestaciones, o por el liberalismo. Ello es así, pues en ese caso, en lugar de identificar los componentes del sistema jurídico y explicar cómo funcionan, dando así cuenta del derecho practicado en una sociedad, se sostendría que al no ajustarse lo observado a los valores considerados correctos por el observador, entonces no hay derecho como tal en dicha sociedad, a pesar de existir coacción, sanciones, derechos subjetivos, procedimientos, competencias u obligaciones.

Huelga insistir en que no se trata de negar vínculos entre los componentes del sistema jurídico y contenidos axiológicos, por ejemplo, entre las reglas, interpretaciones judiciales y actos administrativos, y valores, principios o convicciones provenientes de ámbitos como la moral, la política o la cultura en sentido estricto, así como de las preferencias e intereses de los operadores jurídicos. Esos vínculos existen, son inevitables y la perspectiva analítica no los niega, ni mucho menos los condena como elementos "impuros" 19 .

Por el contrario, los reconoce y los incorpora a su descripción, solo que no hace depender ni la existencia, ni la validez, ni la eficacia del sistema jurídico, de esa relación, que por demás es contingente y no necesaria, y no supone subordinación causal, con fuerza de necesidad, de lo jurídico a lo extrajurídico. Como bien lo permite comprender la perspectiva analítica, combinada con los puntos de vista externo e interno ya referidos, existirá y tendrá validez el derecho aun allí donde no se ajuste a ideales o principios axiológicos considerados correctos por un sector dentro o fuera de esa sociedad, si para la mayoría de los integrantes de ésta aquél es observado en grado suficiente por su pertenencia a un sistema normativo reconocido como derecho, que aporta lo que de él se espera a efectos del funcionamiento social: certeza, seguridad, orden y estabilidad.

Como ejemplos de lo anterior, tenemos que, una norma administrativa puede otorgar a la Administración poderes discrecionales excesivos, contrariando así un contenido del principio del Estado de Derecho defendido por el liberalismo, esto es, como sinónimo de imperio de la ley y no como Rechtsstaat ${ }^{20}$. Asimismo, una norma penal puede castigar una conducta que de forma manifiesta contraríe un principio como la no discriminación, defendido por los iusmoralismos actuales. Ambos principios, incluso, pueden estar positivados en preceptos del sistema jurídico. Sin embargo, mientras sean observados por los destinatarios, o, incluso habiendo sido

\footnotetext{
${ }^{19}$ De hecho, en su análisis sobre la discrecionalidad judicial, Hart y los diferentes exponentes del llamado positivismo incluyente, reconocen la existencia y relevancia de estos elementos, como parte de la práctica jurídica. Al respecto, ver: Rodríguez (2002: 155 y ss.).

${ }^{20}$ Cfr. Pereira Menaut (2003: 25 y 33).
} 
cuestionados por estos, no sean expulsados de manera formal del sistema por una instancia competente para ello, esas normas serán derecho. Corresponderá activar los mecanismos de producción o de control de validez previstos en el propio sistema para lograr la erradicación de los preceptos cuestionados.

Quiere ello decir que, mientras sean válidos y estén vigentes esas normas, vincularán y permitirán ejercer la coacción a las autoridades. Afirmar lo contrario, por muy en contra que se esté de ambas, además de implicar una confusión entre los planos del "ser" y del "deber ser", constituirá una afirmación falsa, divorciada de la realidad, que llevará a las personas a tomar decisiones contrarias a sus propios intereses y su libertad. Aquí se debe aclarar que no se afirma que ambas normas son derecho por un sesgo estatista, proclive a la obediencia a la autoridad estatal, por asimilar derecho a mandatos, o por equiparar derecho y legislación.

Tampoco porque se postule que las personas deban abstenerse de cuestionar los sistemas jurídicos y de actuar para que sean modificados para mejorar su contenido. Se afirma que las normas que permiten la discrecionalidad excesiva y la sanción discriminatoria son derecho tan solo porque es lo real, lo que sucede, la práctica observada y materializada en actos dictados en ejercicio de una potestad administrativa y en penas de prisión impuestas por sentencias con respaldo en una norma que sanciona una conducta determinada.

Para la perspectiva positivista, el derecho es un fenómeno que responde a convenciones sociales, es un sistema normativo particular que coopera con otros sistemas normativos, por ejemplo, con sistemas morales, donde pueden coincidir normas como "no matarás". De acuerdo con un símil empleado reiteradamente por el autor García Amado (2015: 204), la relación entre derecho y moral es como la relación entre el sexo y el amor, en la que uno no siempre lleva al otro. Por ello, no son infrecuentes los componentes de un sistema jurídico irrelevantes en principio para el ámbito de la moral, que son tan derecho como las normas pertenecientes a ese sistema, aunque sean injustas o incorrectas de acuerdo con alguna perspectiva moral. En estos casos, la norma jurídica no deja de ser derecho por ser amoral, inmoral o contraria a cierta idea de justicia.

Téngase en cuenta el caso de una ley sancionada por una mayoría absoluta de congresistas, pues así lo permitía el procedimiento de formación de la ley, en desacuerdo con minorías del Congreso que salvaron su voto o votaron en contra. A pesar de lo anterior, la ley sancionada, además de democrática en términos procedimentales, es válida en términos jurídicos y, si es publicada en el órgano oficial del Estado para que adquiera eficacia, estará vigente, siendo entonces poco realista, y hasta irresponsable, sostener que no es derecho porque no se ajusta a tal o cual principio que defendían las minorías derrotadas en el debate legislativo.

Siguiendo a García Amado (2014), es necesario aclarar que adoptar un enfoque positivista no quiere decir que no se tengan convicciones morales. Kelsen con su oposición al nazismo (Feher, 2014: 181-199) y H.L.A. Hart con sus críticas a la política legislativa en tiempos de Thatcher (Lacey, 2004: 356 y ss.) son prueba de ello. Ahora bien, lo que sí procuran no hacer los positivistas, y en eso resultan más popperianos y responsables en términos intelectuales que algunos liberales y los iusmoralistas, es insistir en que sus convicciones morales deben inundar el derecho de una sociedad determinada como condición para reconocer como derecho al sistema jurídico operante. 
Un jurista que adopte la perspectiva positivista, adopta un enfoque metodológico, no uno axiológico u ontológico ${ }^{21}$. Sigue, pues, la distinción aceptada en ese campo, entre la economía positiva y la economía normativa. No aspira a proponer una teoría del poder, y más bien estaría orientado a proponer una ciencia de la acción humana en el campo del derecho (García-Salmones Rovira, 2013: 266 y ss.), esto es, una ciencia del derecho derivada en última instancia de las decisiones y conductas de los individuos interactuando entre sí y en relación con ciertas normas en una comunidad determinada.

Por ello, jamás sostendrá que una norma que vaya en contra de su moral no es derecho, como sí lo hacen los liberales al sostener que la legislación que no se adecúe a la thesis no es derecho ${ }^{22}$, o los iusmoralistas, cuando no reconocen como derecho una norma que vaya en contra de su moral, aunque esté en el Código Penal y se haya establecido por mayoría parlamentaria democrática.

El enfoque positivista acepta los desacuerdos que subyacen al derecho, es consciente del pluralismo de valores reconocido por Isaiah Berlin ${ }^{23}$ y no estima posible ni conveniente, por ser contrario a la libertad individual, proponerse la "objetivación" de la moral a través del derecho. De allí que en general, algunas civilizaciones, en particular la occidental, hayan aceptado que la moral es un código personal, consensual e intersubjetivo, propio del ámbito de la libertad individual, que no puede ser obligatorio en términos institucionales, mientras que el derecho es el código de todos, reconocido como obligatorio en términos institucionales y respaldado por la coacción formalizada, a pesar de que su contenido sea, en última instancia, definido por instancias habilitadas para ello y no de forma convencional entre todos los destinatarios del sistema jurídico (como lo muestran el caso de las leyes, las regulaciones, las sentencias, los arbitrajes, las declaraciones y pactos internacionales, las potestades, etc.).

Tal vez porque en algún punto de nuestra evolución social e individual como seres humanos (Fischer, 2017) entendimos que, mientras de la moral esperamos criterios para la acción desprovista de coacción en el ámbito de los fines y las preferencias personales o de grupo, del derecho esperamos otras cosas relativas a la vida en común, como estabilidad, previsibilidad, medios no violentos de resolución de conflictos, definición de roles en la sociedad, orden y criterios para la toma de decisiones, como condiciones básicas para la supervivencia en sociedad, a través de intercambios, cooperación y castigo a las conductas socialmente nocivas ${ }^{24}$.

\subsection{La tesis de las fuentes sociales del derecho}

Aparte de la separación conceptual entre derecho y moral, la otra tesis fuerte del positivismo jurídico es la relativa a las fuentes sociales, tesis que viene a recordarnos que el derecho tiene carácter artificial, en el sentido de ser una creación, un invento, o una herramienta hecha, o puesta, por el ser humano para satisfacer sus necesidades. Conforme a esta tesis, por un lado, se refuta la fundamentación divina o racional -como suele ser defendida por las distintas tradiciones iusnaturalistas- de las reglas jurídicas, se ratifica la desconexión conceptual o necesaria con valores

\footnotetext{
${ }^{21}$ En efecto, según Bobbio "lo central del positivismo jurídico no es una valoración positiva del derecho positivo, sino: (i) un approach que nos permite distinguir el derecho real del derecho ideal; y (ii) una teoría de las fuentes estatales del Derecho (la constitución, la ley, el reglamento, el acto administrativo, la sentencia, etc.)". Cfr. Arias Castillo (2013: 17) y ver Bobbio (2001: 37-66).

22 Siendo el caso paradigmático el de Friedrich A. Hayek, señalado en el presente trabajo.

${ }^{23}$ Ver una reciente y lúcida reivindicación de este aspecto de la filosofía moral y política de Isaiah Berlin en Vargas Llosa (2018: 235 y ss.).

${ }^{24}$ Cfr. Figueroa Rubio (2014).
} 
como la justicia, la belleza, la eficiencia u otros -sin desconocer las posibles y presentes conexiones contingentes con tales valores, insistimos- y se afirma que el derecho debe su existencia, vigencia, autoridad, validez y obligatoriedad a la ocurrencia de hechos empíricamente verificables en la sociedad.

La mejor y más depurada explicación de esta tesis de las fuentes sociales la hallamos en la obra de H.L.A. Hart, conforme a la cual el hecho social que da nacimiento al derecho es la presencia de una regla -en el sentido de comportamiento regular de las personas, observable desde una perspectiva externa-, a la cual denomina regla de reconocimiento, que debe satisfacer dos condiciones: (i) expresar criterios de validez que sean aceptados como estándares de conducta oficial por determinadas autoridades; y (ii) contar con la aceptación general de los ciudadanos, quienes en condiciones normales cumplen las reglas de conducta consistentes con dichos criterios de validez ${ }^{25}$. Como correctamente lo señala Himma, todos los autores positivistas, de una forma u otra, están comprometidos con la tesis de las fuentes sociales, si bien pueden tener desacuerdos sobre cuál sea en específico el hecho social que en última instancia explique la existencia de un ordenamiento jurídico (Himma, 2002: 126 y ss.; Waluchow, 2007: 95 y ss.).

La otra cuestión que divide a los autores positivistas, entre positivistas fuertes, o excluyentes, y positivistas suaves, o incluyentes, se debe a la textura abierta de la regla de reconocimiento $(y$, por ende, su posible vaguedad $\mathrm{y} / \mathrm{o}$ ambigüedad, como ocurre con cualquier regla). Así, los primeros interpretan que las fuentes convencionales del derecho se agotan con la constitución, la ley, el reglamento y demás fuentes reconocidas por el Estado, mientras que los segundos estiman que la regla de reconocimiento en ocasiones otorga autoridad también a otros materiales normativos, no necesariamente jurídicos en origen, tales como los principios morales, o determinados estándares aplicables a las políticas económica y social ${ }^{26}$. En cualquier caso, más allá de estos debates, la teoría de la regla de reconocimiento es la mejor explicación para sostener la tesis positivista de las fuentes sociales, a tal punto que hasta los más enconados críticos del positivismo jurídico así lo reconocen $\sin$ ambages ${ }^{27}$.

Esta tesis de las fuentes sociales es capaz de explicar -sin entrar en consideraciones sobre su justificación, lo cual corresponde a otro tipo de esfuerzo intelectual- que ciertas fuentes del derecho hayan prevalecido sobre otras en determinadas circunstancias históricas, políticas y culturales, tal y como ha ocurrido, por ejemplo, con las épocas de esplendor del derecho judicial (el pretorianismo de la tradición romano-canónica, o el common law anglosajón), o con la contemporánea hipertrofia legislativa y reglamentaria bajo el Estado Administrativo en ambos lados del Atlántico ${ }^{28}$, sobre lo cual volveremos. Aparte de ello, la tesis de las fuentes sociales

\footnotetext{
${ }^{25}$ Ésta es una estrategia muy preferible, por claridad y calidad explicativa, a la de la norma fundante básica de Kelsen. Ver Kelsen (2002a: 201 y ss.).

${ }^{26}$ Cfr. Marmor (2002: 104 y ss.).

${ }^{27}$ Por todos, Dworkin (1999: 119).

${ }^{28}$ García de Enterría (2000: 48-49): "La segunda gran crisis de la Ley, y seguramente la más grave, es la producida por la desvalorización que ha seguido a una inflación desmedida de las Leyes como consecuencia de su multiplicación incontenible, que, además, ha sido acompañada de un desarrollo desbocado de normas reglamentarias, que complementan o ejecutan las Leyes. La vieja idea de una sociedad libre moviéndose en el cuadro de unos cuantos Códigos y Leyes, claros concisos y tendencialmente estables, que dejaban a la libertad ciudadana todo el amplio espacio de la vida social así encuadrada con precisión y rigor, esa idea ha dado paso a la situación actual en que la sociedad nos aparece inundada por una marea incontenible de Leyes y Reglamentos, no sólo no estables, sino en estado de perpetua ebullición y de cambio frenético".
} 
no ampara o da cobijo solamente a las fuentes estatales ${ }^{29}$, y es perfectamente compatible con visiones evolucionistas sobre las instituciones ${ }^{30}$, aun cuando en el liberalismo subsista una actitud de hostilidad ${ }^{31}$, o cuando menos de incomprensión o silencio $^{32}$ hacia las tesis del positivismo jurídico. Por último, la tesis de las fuentes sociales es compatible con el ideal regulativo del Estado de Derecho, defendido al menos por el liberalismo clásico (no anarquista) y que supone abogar por límites y controles sobre las autoridades que deben garantizar en última instancia, la correcta creación y aplicación de las reglas jurídicas. Sobre dicho ideal regulativo dedicaremos otra parte de este trabajo.

4. Una caracterización de las críticas contemporáneas más notorias al positivismo jurídico

Habiendo explicado las tesis centrales del positivismo jurídico, nos parece importante efectuar una breve caracterización de las críticas contemporáneas más notorias hechas hacia aquel. Ello el propósito de evidenciar que dichas críticas normalmente fallan en el blanco, dado que los propósitos de estas posturas rivales son muy distintos, pues no van en pos de la claridad conceptual, o con la intención de esclarecer metodológicamente el objeto de estudio, sino con otros objetivos, tales como justificar la agenda política de los tribunales constitucionales, o la consecución de la igualdad material, o la justicia distributiva, o justicia social. Dichas concepciones rivales, por cierto, suelen ser bastante contrarias -cuando no hostiles, como el caso del antipositivismo de Ronald Dworkin ${ }^{33}$ - hacia el liberalismo económico y político clásico.

Los enfoques críticos de la perspectiva positivista, en general, acusan a esta de: (i) no contar con una metodología idónea para operar en la práctica con los actuales sistemas jurídicos, llenos de valores, principios, derechos y otros contenidos axiológicos; (ii) no aportar una estructura conceptual acorde para explicar la relación actual entre derecho y moral derivada de esos contenidos axiológicos; (iii) no destacar la importancia de la actividad jurisdiccional, en especial de la justicia constitucional, en los sistemas jurídicos contemporáneos; (iv) ser proclive a justificar y legitimar cualquier estructura de poder, incluso regímenes autoritarios y totalitarios al equipar derecho a Estado; (v) degradar la calidad y justicia del derecho al equipararlo con la legislación y la regulación, en lugar de proponer criterios metajurídicos para su producción; y (vi) justificar el predominio del sobreabundante derecho legislado por sobre el derecho del precedente, que sería menos estatista y garante de la libertad ${ }^{34}$.

\footnotetext{
${ }^{29}$ Ello es así a pesar de la coincidencia histórica entre el surgimiento de los Estados nacionales y el positivismo jurídico como teoría, lo cual hacer lucir al positivismo como una teoría estatalista (no estatista, que es otra cosa), anclada exclusivamente en las fuentes estatales del derecho. Ver: Bobbio (2015: 107). ${ }^{30}$ Así, por ejemplo, sostenemos que no existe contradicción alguna en afirmar, por una parte, que las instituciones han surgido en muchas ocasiones como consecuencias no deseadas, o planificadas, de la acción humana libre; y por otra parte aseverar que en una sociedad corresponde a determinadas autoridades reconocer, dar fe y hacer valer los postulados de dichas instituciones.

${ }^{31}$ Esa hostilidad hacia el positivismo llega a un punto francamente incomprensible. Así vemos cómo un autor que dice ser liberal -y defensor de las ideas de F. A. Hayek, para ser más específicos- encuentra loable el antipositivismo de Ronald Dworkin, un autor que aparte de antipositivista, también fue claramente contrario a las ideas de libertad económica defendidas por la Escuela Austríaca de la Economía. Cfr. Herrán Alonso (2010: 191, nota al pie).

${ }^{32}$ En un excelente trabajo, el más reciente de teoría jurídica liberal escrito en castellano, esta posibilidad es completamente omitida o silenciada una vez más, pues se parte de la sempiterna -y peyorativavisión liberal del positivismo como una muestra de racionalismo constructivista que va en detrimento de la acción libre individual. Cfr. Rojas (2018: 195 y ss.).

33 Cfr. Vigo (2006: 167 y ss.)

${ }^{34}$ Véase al respecto el ya referido trabajo de Atienza Rodríguez y Ruiz Manero (2006).
} 
Es natural y comprensible que los seres humanos aspiremos a que las instituciones, realidades y resultados de los ámbitos de la política, la economía y el derecho, por ejemplo, se ajusten a modelos ideales, estructurados a partir de una idea propia, interna, a partir del acuerdo con otros, o sobre la base de una tradición dada que se asume como la mejor, más correcta o beneficiosa. Y es legítimo que, siempre que no se ejerza coacción sobre otros, cada quien, a través de la persuasión, la negociación y los acuerdos, de prácticas comunicativas y no de imposiciones arbitrarias, procure que los contenidos de esos modelos sean una realidad para todos.

Un ejemplo de lo anterior puede encontrarse en el complejo proceso políticojurídico que debieron seguir Abraham Lincoln y los abolicionistas para lograr la aprobación en 1865 de la XIII enmienda a la Constitución de los Estados Unidos de América para abolir la esclavitud, en un contexto donde no necesariamente el abolicionismo contaba con el abierto apoyo de la mayoría de los representantes y representados de ese país ${ }^{35}$.

Lo que no es comprensible, al menos desde una perspectiva positivista, es que se pretenda imponer a través del derecho contenidos morales, políticos o de índole similar, mediante atajos que eviten el debate público según prácticas democráticas y argumentativas, y mediante decisiones que adopten la fuerza de cosa juzgada. Menos aún, si lo que se busca es establecer una moral objetiva, esto es, de una idea de bien definida por la autoridad y no elegida o acordada por las personas, respecto de los diversos problemas morales que se suscitan en la sociedad.

Para el enfoque analítico y descriptivo aquí sostenido, el derecho comienza a perder su consistencia interna, su eficacia y más allá, su autonomía como sistema normativo, cuando desde una visión iusmoralista o alguna similar se pretende desconocer sus fuentes sociales. Lo mismo ocurre cuando, a partir de instancias de poder, y con la excusa de hacer más justo o legítimo dicho sistema, se lo comienza a subordinar a otro sistema normativo, como puede ser la moral, solo que en este caso un sistema particular y no general, desde el cual no solo se imponen contenidos morales no necesariamente aceptados por el conjunto de las personas, sino también se desnaturalizan los componentes del derecho, tanto a nivel práctico como a nivel analítico y conceptual.

Que el Estado sea de justicia y no de derecho, que la vivienda digna sea un derecho subjetivo y no una forma de propiedad privada, que la democracia sea "directa" y no representativa con mecanismos de participación, que la justicia constitucional pueda sustituir a los Poderes Públicos en lugar de resolver controversias constitucionales, que el aborto, el matrimonio igualitario o la discriminación positiva estén permitidos, entre otros, son asuntos de alta política, que involucran importantes disputas morales, ante las cuales es la discusión abierta, democrática y parlamentaria, la que debería prevalecer, en lugar de someterse al formal y muy limitado debate judicial, como algunos enfoques recientes del derecho, en general antipositivistas, proponen.

Ejemplos de estos enfoques que denominamos aquí, siguiendo a García Amado, iusmoralistas ${ }^{36}$, se encuentran en la obra de R. Dworkin, R. Alexy y C.S Nino, entre otros, así como en los trabajos de quienes adhieren sus tesis, como son el neoconstitucionalismo y la hermenéutica jurídica. Pero curiosamente, también están presentes en algunas tradiciones liberales, en las que la falta de correspondencia entre uno o varios componentes de un derecho positivo con el ideal jurídico de esas

\footnotetext{
35 Proceso descrito en el apasionante relato de Kearns Goodwin (2006).

${ }^{36}$ Ver sobre el tema: García Amado (2015).
} 
tradiciones, es suficiente para considerar a ese o esos componentes como no derecho, negando así la perspectiva de las fuentes sociales -no necesariamente estatales- del derecho.

Como puede verse, ya sea a través del razonamiento de los erizos que logran la única solución correcta en los casos difíciles (Dworkin), del método de la ponderación para resolver según la razón conflictos entre valores o derechos del mismo rango (Alexy) o de la construcción racional de soluciones jurídicas a salvo de excesos de discrecionalidad (Nino), se plantea en estos enfoques la posibilidad de establecer racionalmente desde el derecho un sistema de valores morales objetivo y, a partir de él, un conjunto de respuestas y soluciones correctas, justas, a la totalidad de los problemas prácticos que se generen en una sociedad, y en que sea necesario o posible emplear la coacción para resolverlos.

En el caso del neoconstitucionalismo, en general, se propone el paso de un Estado de Derecho a un "Estado de derechos", con énfasis en la protección y garantía de derechos fundamentales "prestacionales", asumir la Constitución como un programa axiológico, el predominio en la interpretación judicial del derecho de los valores, principios y derechos fundamentales contenidos en el programa sobre las reglas, el abandono de la separación entre derecho y moral a partir de la Constitución, la existencia de una justicia constitucional con funciones adicionales a la jurisdiccional y el cuestionamiento de la tradicional tesis de la división del Poder Público ${ }^{37}$. Peor aún, en algunos casos se invocan supuestas prácticas o identidades culturales para sostener la existencia de un sistema jurídico sui generis, que solo es tal en la medida que reivindica a los genuinos practicantes de dichas prácticas ${ }^{38}$.

En paralelo al neoconstitucionalismo, con algunas diferencias entre sí, avanza el enfoque del derecho como argumentación, liderado, entre otros, por Atienza Rodríguez (2012), el cual sostiene que el derecho más que un sistema normativo es una práctica argumentativa constante, susceptible de objetivación ética, por lo que niega que exista una separación entre moral y derecho, y a partir de allí que una norma injusta sea una norma jurídica. En este enfoque, explícitamente antipositivista, existe entonces una moral por encima del derecho, que lo condiciona y por tanto es la "objetivamente verdadera".

Coindicen todos los enfoques anteriores en ser variantes de un objetivismo constructivista en el plano de los valores y principios morales y de otra índole. El enfoque positivista, debido a su preocupación analítica, no ontológica ni metafísica, y a su perspectiva externa o descriptiva sobre la producción y funcionamiento del derecho en cualquier sociedad, no acepta tal posibilidad, y más bien reconoce la existencia de un sano y tal vez insuperable relativismo o pluralismo moral, el cual, a través de las fuentes sociales -tanto las estatales como las no estatales o privadaspermean el contenido del derecho, pero sin afectar ni desnaturalizar los componentes del sistema, en tanto no los subordinen a una determina moral intolerante o excluyente de otras posibles que puedan incidir en el ordenamiento a través de leyes, contratos, regulaciones o interpretaciones, y no impidan satisfacer expectativas que en general tienen de él las personas, y mantienen abierta la posibilidad del cambio.

Otros enfoques críticos de la perspectiva analítica y descriptiva del derecho son los desarrollados por la "hermenéutica jurídica", una orientación que tuvo sus inicios en el siglo XIX. Como lo ha explicado García Amado, estos enfoques, siguiendo a Gadamer, proponen "una ontología jurídica que ve el derecho como objeto en

\footnotetext{
37 Ver Barberis (2003) y Pozzolo (2003).

${ }^{38}$ Como se hace por ejemplo en Viciano Pastor y Martínez Dalmau (2011).
} 
permanente constitución en un proceso circular entre una creación de normativa que es siempre interpretación, y una interpretación de enunciados normativos que es siempre, también, creación normativa"; y asimismo, la pérdida de sentido de "la pretensión de una teoría normativa de la interpretación jurídica, y el deseo de no renunciar por completo a la indicación de reglas que nos salven de la arbitrariedad o el subjetivismo del intérprete judicial" (García Amado, 2003: 219-240). Aquí la interpretación pasaría a describir y agotar la totalidad de lo jurídico, donde interpretar supondrá mucho más que la atribución de significado a un texto ${ }^{39}$.

La legislación, la regulación, los contratos y demás actos jurídicos, distintos a la sentencia judicial -o al acto administrativo, por ejemplo-, serían casi por completo irrelevantes al momento de identificar y utilizar el derecho, pues asemejándose en ello a lo sostenido por los enfoques realistas, será lo que en esas sentencias se establezca, a través del complejo proceso hermenéutico (interpretativo en términos de comprensión histórica, estética y lingüística), y no lo prescrito en las normas del sistema jurídico, lo que es derecho.

En el caso de las críticas formuladas por el liberalismo, como ya se indicó, éste sostiene que el enfoque positivista degrada al derecho y es negativo para las personas en tanto acepta como parte del sistema jurídico normas que pueden ser contrarias a la libertad individual, por ejemplo, la aplicación de mandatos y no de leyes en sentido estricto a la conducta de los particulares.

Lo es también porque reconoce como fuente de derecho a los actos estatales, en lugar de solo reconocer como tales a las fuentes no estatales identificadas por la teoría evolutiva de las instituciones sociales (Martínez Meseguer, 2009: 207 y ss.). Para este sector del liberalismo, se podrá reconocer como derecho a las normas, principios, valores y demás componentes o piezas que resguarden la libertad individual y limiten el poder de la autoridad y cualquier aceptación o reconocimiento de algo diferente como derecho, es una justificación autoritaria del poder y, por tanto, antiliberal.

Las posturas liberales que sostienen lo anterior, adoptan un significado de positivismo inadecuado para describir el enfoque analítico aquí examinado. Ni H.L.A. Hart, ni Bobbio ni Carrió, por ejemplo, adoptaron un enfoque ideológico sobre el derecho, sino uno descriptivo, que dejara a otras disciplinas la discusión acerca de los contenidos que debiera acoger el sistema jurídico -tipo de contratos, de potestades, de derechos, de obligaciones, de penas, y demás cuestiones sustantivas. Por ello, el enfoque aquí defendido implica reconocer como legítimo, correcto o justo a aquel sistema jurídico que no garantice la libertad individual, por ejemplo.

Acusar de ello al positivismo como enfoque descriptivo equivaldría a acusar a Mises de ser socialista por aceptar y reconocer que la planificación central es un sistema económico, lo que resulta absurdo. Se reconoce como derecho lo que funciona como tal tanto para el conjunto de las personas de una comunidad como para la autoridad que opera en ella, no obstante el grado de rechazo parcial o total que el contenido de aquél pueda generar.

\footnotetext{
39 Cfr. Orunesu (2012: 213 y ss.). En un trabajo sobre el pensamiento de Arthur Kaufmann, otro importante autor de la tradición hermenéutica, Serna Bermúdez (2005) describe los elementos comunes de dicha tradición, siendo entre ellos el más importante la revaloración del sujeto en la comprensión de la realidad (o, dicho de otro modo, el intento de superar la dualidad sujeto-objeto), lo cual, en el plano jurídico se plasma especialmente en las tareas creativas y valorativas del juez y en el rechazo a la metodología jurídica considerada ortodoxa.
} 
Dejará de ser derecho, por ejemplo, en la medida que la autoridad de forma deliberada y creciente no se ajuste a lo que el sistema jurídico establezca, o que los particulares dejen de utilizar sus componentes y empleen otros mecanismos para relacionarse entre sí, para aplicar sanciones o recompensas. En definitiva, cuando sus contenidos ya no atiendan a sus fuentes sociales, y deje de ser reconocido como obligatorio, como vinculante, tanto por autoridades como por particulares. No por vulnerar la libertad, los Derechos Humanos o la justicia. Si hace esto será un derecho inconveniente, perjudicial, pero no dejará de ser derecho.

Varias de las corrientes críticas anteriores se autodenominan post-positivistas. Invitan a abandonar el enfoque positivista por ideológico o por inútil. Sin embargo, es importante advertir que varias de esas corrientes o enfoques no son ni aspiran a ser teorías del derecho. En algunos casos son aproximaciones filosóficas a los problemas teóricos y prácticos del derecho. En otros casos, son enfoques normativos o prescriptivos extrajurídicos de lo que el derecho debería ser. Finalmente, en otros casos son reflexiones críticas de una tradición que genera insatisfacción y frustración intelectual, por evitar la multiplicación de esencias así como la confusión entre lo que es y lo que deseamos que sea el sistema jurídico.

Mas ninguno de ellos cumple mejor la tarea de identificar, describir y explicar cómo funciona el derecho, esto es, las normas que gozan de respaldo institucional en una sociedad para ser impuestas coactivamente, a partir del reconocimiento social como derecho de esas normas, que la perspectiva analítica y descriptiva reimpulsada en el siglo XX por H.L.A. Hart, Bobbio y Carrió, entre otros. Dicha perspectiva se encuentra más cercana al empirismo que al racionalismo y al progresismo y, por tanto, se muestra más compatible con la garantía de la libertad individual que cualquier otro punto de vista que haga depender la validez del derecho de la moral u otras fuentes no sociales.

\section{5. ¿Se sostiene la crítica liberal al positivismo jurídico?}

Una de las posiciones antipositivistas que requiere mayor atención es la que proviene del pensamiento liberal. Un autor tan prominente del liberalismo como Hayek identfica al positivismo jurídico con la legislación contraria a la libertad individual, con la razón constructivista frente a su cosmos y su catalaxia (orden espontáneo, o proveniente de las consecuencias no deseadas) y, en fin, ve al positivismo como un conjunto de ideas erradas, con secuelas fatales para las libertades políticas y económicas. Como contraparte al positivismo, la posición hayekiana ve con buenos ojos la defensa del common law -el sistema anglosajón de decisión judicial mediante el establecimiento de precedentes- como única posibilidad para limitar la arbitrariedad del poder por medio de un derecho espurio.

Es cierto que Hayek advirtió sobre lo problemático de emplear la expresión "Derecho natural" al distinguir el derecho reconocido y respaldado por los no positivistas, del que reconocían -y no necesariamente respaldaban- los positivistas de su tiempo. Reconoció que en dicha expresión subyacía la tendencia a aceptar la existencia de un orden racional dado, superior en su contenido axiológico, pero desvinculado de la acción humana y, por tanto, muy cercano a los modelos utópicos colectivistas $^{40}$. Pero esa advertencia no fue suficiente para permitir a Hayek -y a los

\footnotetext{
40 Cfr. Montoya y González Altable (1993: 30): "Habría igualmente que matizar la interpretación de la filosofía jurídica de Hayek como un intento de restauración de la idea de ley natural, sociológicamente interpretada. Pues a la idea clásica de ley natural le era esencial la inclusión de un método por el que el contenido de la ley podría ser esclarecido. Como hemos visto, nada de esto se encuentra en Hayek que, con respecto al problema de los contenidos de los principios de justicia, adopta una postura más cercana
} 
liberales en general que reflexionan acerca del derecho- desarrollar una filosofía y teoría jurídicas consistentes, útiles en la práctica, que sirvieran para identificar y evaluar los componentes de un sistema jurídico cualquiera, así como su funcionamiento. Asimismo, tampoco lo liberó de la inconveniente tendencia a aludir al Derecho natural y sus derivados, como los derechos naturales o la "naturaleza humana", vía teoría evolutiva de las instituciones sociales, tal y como lo hacen también otros destacados pensadores liberales, como Leoni o Rothbard ${ }^{41}$.

Lo cierto es que no existe semejante orden superior, coherente, justo y garante de la libertad al que basta con "descubrir", "reconocer" y "seguir" para impedir el abuso del poder y asegurar el imperio de las reglas sobre los mandatos.

El racionalismo metafísico implícito en el discurso naturalista liberal, le impide advertir que la ya aludida teoría evolutiva aclara que lo que en definitiva en cada sociedad se reconoce como derecho, responde a consensos, acuerdos, elecciones y prácticas sostenidas en el tiempo por las personas, que no siempre o necesariamente terminan siendo beneficiosas para la libertad. De ningún modo, la aludida teoría evolutiva supedita lo jurídico a una suerte de verificación de la compatibilidad de una institución con el contenido del derecho natural o alguna otra fuente no social.

Justo por su enfoque descriptivo y no metafísico, la teoría evolutiva de las instituciones - defendida en gran medida por Hayek- conecta más y mejor, en su análisis de lo jurídico, con la tesis de las fuentes sociales del derecho propuesta por el positivismo, más empirista que formalista, desarrollado por autores como H.L.A. Hart. Por el contrario, la tesis liberal de la existencia de principios evidentes, derechos inherentes o valores superiores determinantes del contenido del derecho, a efectos de su reconocimiento como legítimo sistema normativo de coacción, no encaja bien con la teoría evolutiva de las instituciones ${ }^{42}$.

En los hechos, en las sociedades se reconoce como derecho a ciertas normas, hábitos, principios o valores más por una combinación de aceptación voluntaria y temor a la sanción, que por la realización que estos últimos hagan de ciertos contenidos axiológicos, como por ejemplo, los que defiende el liberalismo, los cuales

al formalismo de Kant, como si las leyes justas pudieran establecerse partiendo de la misma forma de ley".

${ }^{41}$ A pesar de que intentó hacerlo en Hayek (2006: 255 y ss.), pues al afirmar que "el Derecho está al servicio de un orden social [en el que] las acciones que solo conciernen a los individuos que las realizan no deberían estar sujetas al control del derecho, por más fuertemente que puedan estar reguladas por la costumbre y la moral", asume que existe un único orden social justo o correcto, por así determinarlo la razón o la experiencia, pero no un acuerdo tácito o expreso, mediante un reconocimiento verificable en los hechos, de quienes se encuentran sometidos a ese Derecho. En definitiva, Hayek y en general los defensores de la tesis de la existencia de un único orden social justo no aceptan una tesis alternativa, más ajustada a la contingencia social que deriva de la libertad de las personas, como es la tesis implícita en la formulación de la regla de reconocimiento hartiana y la sostenida sobre el carácter convencional de los derechos humanos, basada en emociones como la empatía, la vergüenza y el cuidado de sí, expuesta en Hunt (2009).

42 Para Santanatoglia (2008: 184), el desacuerdo entre la teoría jurídica de Hayek y el positivismo jurídico "no se da meramente al nivel de las nociones jurídicas que cada uno propone sino al nivel de sus presupuestos filosóficos y epistemológicos". El problema se centraría en las nociones de racionalidad limitada y conocimiento disperso: Hayek considera que las reglas de conducta no pueden conocerse plenamente con anterioridad a la decisión de un juez, quien, en todo caso, sólo puede intentar "descubrir" tales reglas y aplicarlas al caso concreto. La explicación de dicha autora tiene sentido para nosotros, pues así como Hayek y la Escuela Austríaca de la Economía denuncian la imposibilidad del socialismo, al entender que en éste no existe cálculo económico sino imposiciones del Estado, mutatis mutandis, la tarea del positivismo jurídico de pretender describir los sistemas jurídicos se vería imposibilitada por su reconocimiento como jurídico sólo aquello puesto o decidido por la autoridad estatal, cuando las reglas de conducta serían producto del orden espontáneo de la sociedad. 
en todo caso deben competir con otros que se le oponen, como los del socialismo, por lograr la preferencia de las personas.

También, por lo expuesto, la permanente crítica al derecho puesto por los órganos estatales como manifestación de una deformación o degeneración per se de los sistemas jurídicos, termina siendo una crítica débil cuando se funda en ese supuesto orden superior natural, derivado de la razón universal, colectiva o natural. La teoría evolutiva liberal, como la de Hayek, admite que en el momento de la "institucionalización" de las normas jurídicas, interviene una autoridad, una instancia a la que socialmente se la asigna esa labor, y ello per se no es un acto arbitrario, contrario a la libertad de las personas.

Siempre se podrá y deberá debatir cuánto derecho debe positivizar el Estado y cuánto la sociedad civil, el mercado, etc., así como, especialmente, qué tipo de derecho, y conforme a qué criterios, deben poder en un sector y en otros. Lo que no tiene sentido decir es que el derecho deja de ser tal, primero, si no respeta y garantiza la libertad individual, y segundo, si es producido principalmente por la autoridad gobierno, congreso, jueces-, en lugar de por las personas a través de arreglos voluntarios. Podrá ello afirmarse en un plano prescriptivo, normativo, pero no descriptivo y empírico.

Que, en algún período de la historia, el derecho haya sido producido en mayor medida por los particulares que por la autoridad, y ello haya resultado beneficioso en varios sentidos, puede ser cierto e importante conocer. Pero que a partir de cierto momento a la fecha sea mayor el derecho elaborado por la autoridad, a través del Estado moderno, no tiene por qué asumirse como algo que haga menos jurídicos a los sistemas compuestos en su mayor parte por legislación, regulaciones y criterios judiciales, dictados por autoridades estatales.

Si los componentes de un sistema jurídico logran los cometidos que todo grupo humano espera de su derecho, esto es, cierto grado de previsibilidad de las conductas, castigos a las transgresiones, posibilidad de intercambios y definición de quiénes competen las tareas asignadas al Poder Público, y a través de qué procedimientos, entonces en esa sociedad hay derecho, realice éste o no el ideal político liberal del Estado de Derecho, por ejemplo.

Otra cosa, y el enfoque positivista aquí sostenido en modo alguno se opone a ello, más bien, lo potencia y estimula, es que los integrantes de cada sociedad actúen para que los componentes de su derecho cada vez aseguren de mejor forma la libertad, por ejemplo, teniendo en cuenta la fundamental diferencia, conceptual y no forzosamente institucional, entre nomos y thesis, y en qué medida ésta debe tener en cuenta a aquél (Hayek, 2006: 155 y ss.).

Lograr que legisladores, jueces o reguladores operen con esa distinción es muy útil para mejorar la calidad del derecho de un país, pero no para responder a un posible inversionista, a un trabajador inmigrante, a la parte de un arbitraje de equidad o a un interesado en afiliarse a una asociación civil, cuáles son los costos tributarios de iniciar un negocio, cuáles los requisitos para la contratación laboral de extranjeros, cuáles son las reglas para que el arbitraje sea válido o cuáles las obligaciones que asumen los miembros de esa asociación. Estas últimas se responden, con sus consecuencias más o menos beneficiosas para las personas, a partir del derecho puesto por la autoridad o por las personas y no por lo que la naturaleza o la razón, constructivista o no, sostenga. Por último, insistir en que derecho es solo lo que de acuerdo con estas fuentes no sociales se considere es, implica abrir la posibilidad de 
que unos pocos "conocedores" de ese saber superior, una vez asumido el poder para ello, lo impongan en nombre del bien de todos ${ }^{43}$.

Es poco práctico sostener que el positivismo es el responsable de que se haya debilitado el sistema del common law -aquel sistema anglosajón de decisión mediante precedentes- $y$ fortalecido el sistema del derecho legislado, primero, porque aspirar un retorno a aquél es poco realista, y segundo, porque tampoco el sistema de precedentes es en sí mismo garantía de límites al poder (de hecho, muchos de esos precedentes sostenían una serie de prerrogativas que iban en detrimento de lo que entendemos por Estado de Derecho).

Constituye un grave error conceptual del liberalismo equiparar positivismo a normativismo, y peor aún a teoría justificativa del contenido y obediencia de la legislación ${ }^{44}$. El positivismo, en el sentido dado en este trabajo a ese término, como ya se ha explicado, no es una filosofía, una ideología, o una teoría política, sino un método de identificación, análisis y evaluación de los componentes de un sistema, de un conjunto, llamado derecho. Nada más. A ese método, en su labor, le resulta igual si esos componentes los pone la autoridad o los ponen las personas, igual los identificará, reconocerá y evaluará, desde los criterios, por supuesto, con que le corresponde trabajar.

Entonces, el positivismo reconoce como derecho a la legislación o la regulación, por cierto, en modo alguno porque los dicte la autoridad, sino porque socialmente, las personas de carne y hueso, a partir de ciertos hábitos, costumbres, prácticas y consensos, así lo aceptan y lo reconocen. De igual forma, el positivismo reconoce como derecho, por las mismas razones, a los precedentes judiciales, a los contratos y, en general, a toda fuente de obligaciones reconocida como tal por quienes quedan vinculados a los componentes de ese derecho o sistema jurídico.

El problema, desde el punto de vista de la garantía de la libertad, más que desde la existencia del derecho, es que al disminuir el derecho positivizado través de precedentes y aumentar el puesto a través de la legislación y la regulación, a través de estas otras fuentes se haya incrementado el poder de la autoridad y reducido el ámbito de libertad de las personas. Pero esto ha ocurrido no porque el positivismo diga que eso es correcto y sea necesario para que funcione el derecho, sino porque en las autoridades productoras de derecho por esas vías han influido más y mejor las ideas contrarias a la libertad y favorables al estatismo, los poderes discrecionales y el intervencionismo, cuando no al autoritarismo, que las ideas que promueven y garantizan la libertad.

Tal influencia mayor, por lo demás, lo que muestra es cierta dificultad del liberalismo en su capacidad de convencer a más personas en el ámbito de la discusión de las ideas sobre cómo conducir a las sociedades. Deberían los liberales no atribuir al positivismo lo que es exclusiva responsabilidad suya.

Luego, hay dos razones más por las cuales la crítica del liberalismo hayekiano al positivismo a partir del tránsito del derecho del precedente al derecho legislado es, además de precaria, algo inútil. Primero, porque aspirar que incluso en los países en los que aquél predominó en algún momento vuelva a hacerlo, es poco viable considerando los cambios institucionales y sociales que en ellos han operado,

\footnotetext{
43 En conexión con este punto, nos parece importante destacar la labor de un autor italiano que, sin incurrir en el llamado positivismo ideológico, ha hecho una defensa política y ética del positivismo jurídico muy interesante: Uberto Scarpelli (1997). Sobre la obra de Scarpelli y su defensa del positivismo, ver también: Morales Luna (2013).

${ }^{44}$ Como se hace en Hayek (2006: 244 y ss.).
} 
justamente con motivo del desarrollo económico y social de las personas que los habitan. Una cosa es que la práctica del precedente se mantenga, por la utilidad que ello supone en términos de coherencia, certeza y eficacia del Estado de Derecho, de modo que los precedentes, en especial los beneficiosos para las personas, continúen vigentes en el tiempo, y otra que el precedente predomine respecto de la legislación y la regulación.

Las sociedades capitalistas del siglo XXI no son las sociedades precapitalistas de los siglos XVI, XVII y XVIII. Que haya exceso de legislación y regulación y que buena parte de ella sea, además de perniciosa, de muy mala calidad, nadie lo duda. Pero, de todos modos, son derecho, e institucionalmente es casi imposible revertir su predominio sobre el precedente, por lo que el desafío, lejos de deprimirse o hundirse en la nostalgia del tópico "todo tiempo pasado fue mejor", es trabajar duro porque la legislación y la regulación contengan un derecho favorable a la libertad.

Segundo, porque tampoco el sistema de precedentes es en sí mismo garantía de límites al poder. Los jueces del medievo e inicios de la modernidad tampoco son los mismos jueces del siglo XXI. Las ideas y la posición institucional de aquéllos era una y la de los jueces de hoy es otra. Puede que, en esos siglos anteriores, por el contexto, las ideas y creencias predominantes, los jueces tanto del common law como del civil law tuvieran una concepción sobre su propia función más cercana a la defensa de la libertad de la que pueden tanto unos como otros tener en la actualidad al ser parte de estructuras organizativas regidas por principios como la competencia y la jerarquía.

Hoy los jueces actúan hacia el interior del Poder Judicial, que es una organización, no un servicio privado, y que cuando opera con independencia e imparcialidad brinda la más importante y humanamente realizable garantía de juicio justo a las personas, sin olvidar la tarea, también relevante, que realizan los medios alternativos como el arbitraje y la mediación, por ejemplo. Ahora bien, no existe forma alguna de sostener que un derecho por precedentes tenderá a ser más liberal que un derecho legislado o contenido en regulaciones, pues los jueces pueden ser tan o más estatistas, colectivistas o intervencionistas que los legisladores y reguladores.

Es más, con la influencia actual de los iusmoralismos, el neoconstitucionalismo y las teorías hermenéuticas y posmodernas en el campo de la filosofía y la teoría jurídica, es muy factible que en cualquier sistema jurídico, los jueces estén más dispuestos que nadie en el Estado a reducir los ámbitos de libertad de sus conciudadanos, en nombre del bien común, los Derechos Humanos, el ambiente o la igualdad. De nuevo, toda fuente social del derecho, sean estatales legislativas, estatales regulatorias o estatales judiciales, o privadas negociales 0 arbitrales, pueden y de hecho producen derecho deficiente, autoritario o perjudicial a las personas, pero a pesar de ello es derecho lo que producen, si socialmente es así reconocido por las personas.

$\mathrm{Ni}$ es factible una vuelta al sistema del precedente predominante, ni aunque lo fuera ello sería per se garantía de que tendríamos un derecho más liberal, tanto más porque el derecho, cuando de desborda el activismo judicial y se avanza hacia el gobierno de los jueces, se torna menos liberal, se aleja más de las discusiones y los acuerdos públicos democráticos, y se convierte más en la imposición por parte de los jueces. Ello es patente cuando dicho activismo lo llevan a cabo los tribunales supremos y sobre todo los tribunales constitucionales, los cuales suelen hacer pasar como derecho sus propias creencias, valores y convicciones, por más que se correspondan en contenido con lo que las personas esperarian que se reconozca como derecho. 
Finalmente, una de las críticas más débiles que desde el liberalismo se realiza al positivismo es la que sostiene que este potencia el autoritarismo en perjuicio de la libertad individual (Hayek, 2006: 238) ${ }^{45}$.

Se afirma que es promotor de mandatos en lugar de reglas, debido a su supuesta tendencia a legitimar a la autoridad, tenga ésta la forma que tenga y a permitir y tolerar cualquier contenido en los componentes de los sistemas jurídicos, tanto por su tesis sobre la separación entre derecho y moral, que ya tratamos, como por su "conformismo" abstracto de limitarse a estudiar conceptos, figuras, instituciones y conductas, en lugar de adoptar los correctos, verdaderos y mejores valores o principios, y afirmar sin objeciones que solo si éstos son asumidos por los componentes del sistema jurídico, éste último puede aspirar legítimamente a ser reconocido como derecho, provenga de forma predominante de la autoridad o de los particulares.

Al respecto, valga señalar, primero, que solo con apoyo en una teoría analítica precisa, completa y coherente, en su lenguaje, ámbito de aplicación y consistencia interna, es que el ansiado equilibrio entre autoridad y libertad podrá lograrse, y no a través de cuestionamientos retóricos, anarquistas o nostálgicos, como son los que se formulan apelando a lo "natural", a la eliminación de la autoridad estatal o la vuelta a un supuesto pasado menos autoritario.

Segundo, que esta crítica desconoce la función del método y lenguaje analítico al momento de identificar y operar con los componentes de un sistema, en este caso, el jurídico, ya que su rol no es el de legitimar, o dar razones para considerar correcto, o incorrecto, moral o inmoral, justo o injusto, el contenido, uso y efectos de un determinado componente, ya que se ocupa de la función, y no de su corrección. Y tercero, que no al estudiar las reglas, en obras como la de H.L.A. Hart al menos, se analizan diferentes tipos de reglas, la de reconocimiento, las primarias (de conducta) y las secundarias (de reconocimiento, de cambio y de adjudicación) ${ }^{46}$.

Es con el uso de nociones analíticas consistentes de Constitución, norma jurídica, derecho subjetivo, obligación, deber, sanción, daños, reglas, principios, responsabilidad o fuente, que se puede argumentar mejor por qué los llamados "derechos sociales" no son en realidad derechos, o por qué no todo el derecho que rige en una sociedad es estatal. También solo con apoyo en aquéllas es que resulta posible explicar al interior del derecho, por qué las normas que rigen la actuación de la autoridad deben asumir la estructura de mandatos, dando base al principio de legalidad, y por qué las que rigen a los particulares deben asumir la estructura de reglas, dando así soporte al principio de autonomía de la voluntad.

El positivismo propuesto por Bobbio, H.L.A. Hart y Carrió permite lograr lo anterior con mucha más eficacia que el iusnaturalismo o el iusmoralismo que tanto ha entusiasmado y continúa entusiasmando a los liberales. En esos enfoques, es mucho más complejo llegar a nociones estándar de Constitución, norma jurídica, derecho subjetivo, obligación, deber, sanción, daños, reglas, principios, responsabilidad, fuente, etc., ya que, en ellas, en general, lo que termina definiendo todo lo anterior son las propias preferencias del que las propone, y no la observación de las prácticas, conductas, acuerdos e instituciones que, en la práctica, les dan unidad, consistencia y permanencia.

\footnotetext{
45 El pensador austríaco, de forma paradójica, terminó incurriendo en la misma falacia usada por los juristas nacionalsocialistas al momento de "justificar" su obediencia a normas y órdenes contrarias a la dignidad humana, consistente en atribuir al enfoque positivista la responsabilidad de tal proceder.

46 Ver Guastini (2014) y Squella Narducci (2014).
} 
Pretender, en cambio, demostrar que los derechos sociales no son derechos porque no son derechos naturales, por ejemplo, es mucho más complicado y probablemente menos posible, así como explicar a una autoridad por qué, más allá de los resultados negativos, es desde el punto de vista del funcionamiento de un sistema jurídico en que se reconoce la autonomía de la voluntad, el libre desarrollo de la personalidad o la libertad individual, por ejemplo, aplicar mandatos a los particulares y reglas o, peor aún, principios, a las autoridades.

Acusar al positivismo de que es amoral porque estos análisis los hace sin entrar a valorar el contenido de las figuras o instituciones que analiza, es como acusar de lo mismo al análisis económico del derecho cuando analiza una decisión o acción jurídica. Ese método no se pronuncia sobre la corrección ética, moral o política de una acción, sino sobre lo racional e irracional que resulta para el agente, en términos por ejemplo de costos y beneficios, el adoptar esa decisión o acción. No se debe confundir la explicación de cómo algo se estructura y funciona, con la evaluación de cómo ese algo es legítimo o ilegítimo en términos morales, políticos o éticos.

Que el positivismo, en todo caso, reconozca a la autoridad como referencia principal para analizar, no es culpa suya, sino de que en la realidad social de todo país funcione alguna forma de autoridad para la toma de ciertas decisiones, respaldadas por la posibilidad legítima de ejercer coacción. No hay hasta ahora sociedades humanas que funcionen sobre la base de exclusivos acuerdos voluntarios sin respaldo de una autoridad capaz de emplear la coacción para forzar el cumplimiento de esos acuerdos, en caso de negativa injustificada a ello. Tampoco el anarquismo, como orden político, ha podido ser aplicado en alguna sociedad humana. El positivismo -sobre todo el positivismo incluyente- es realista, empirista, no romántico ni metafísico, y por tanto, incluye en su análisis lo que existe, aportando además insumos de mucha utilidad para valorar y pensar, ya no a nivel descriptivo sino prescriptivo, cómo mejorar lo que existe.

En tal sentido, hasta que el liberalismo o las demás tendencias antipositivistas con las que, curiosamente, aquél termina hermanado, no desarrollen desde sus postulados axiológicos estructuras analíticas para trabajar con los componentes de los sistemas jurídicos, esto es, un conjunto de conceptos eficaces, pautas y métodos de producción, interpretación y aplicación del derecho y, desde luego, criterios para el permanente mejoramiento del sistema de acuerdo a esos postulados metajurídicos, será el positivismo jurídico, a pesar de los prejuicios, la mejor teoría jurídica existente para la defensa de la libertad individual y la limitación de la arbitrariedad del poder estatal.

6. Las amenazas actuales al Estado de Derecho y, por ende, a la libertad individual

La relación entre el positivismo jurídico y el Estado de Derecho se halla enturbiada por el hecho, ya señalado, de la caricatura deformante según la cual el positivismo sirve para defender y justificar cualquier ordenamiento jurídico, así sea uno despótico y negador permanente de la libertad individual. ¿Cómo podría calzar adecuadamente, entonces, el Estado de Derecho? Peor aún: Hans Kelsen, el autor más tergiversado del positivismo -y de la filosofía y teoría del derecho-, es acusado de confundir las nociones de Estado de Derecho y de ordenamiento jurídico, por su famosa afirmación según la cual "todo Estado es un Estado de Derecho". Veamos.

En primer lugar, para nosotros está claro que, si bien las tesis fuertes del positivismo jurídico ya comentadas (la separación conceptual entre derecho y moral, así como las fuentes sociales del derecho) permiten identificar un sistema jurídico independientemente de su contenido, con lo cual, a manera de ejemplo, el 
ordenamiento jurídico de la Roma antigua debe considerarse fue derecho, no obstante haber previsto, entre otras cosas, la esclavitud y un régimen claramente discriminatorio hacia la mujer. ¿Eso convierte al positivismo jurídico en una teoría que justifica ese tipo de realidades? De ninguna manera. Ni una palabra hay sobre ello. Lo que sí proporciona el positivismo jurídico es un marco conceptual apto para identificar un sistema jurídico como derecho. ¿Eso será mucho o será muy poco? Nos parece que lo suficiente, pues una teoría debe servir de utilidad para al menos identificar con cierta claridad su objeto de estudio. ¿Qué ganaríamos con restar la condición de "derecho" al sistema jurídico de la Roma antigua, o al marco normativo de las monarquías absolutas de hace apenas dos siglos, porque preveían contenidos que hoy chocan con nuestra moral individual, con la moral social o con la moral positiva? Creemos que nada, salvo dificultar nuestras tareas descriptivas y valorativas sobre el fenómeno jurídico, al entremezclar ambas tareas, como lo hace el iusmoralismo actual ${ }^{47}$.

Kelsen de nuevo: el autor praguense jamás confundió el derecho (ese fenómeno que podemos identificar gracias a la teoría positivista, a partir del hecho empíricamente verificable de la existencia de una regla de reconocimiento) con el Estado de Derecho (el ideal regulativo del constitucionalismo moderno que se compone con el principio de legalidad, la separación de poderes y el reconocimiento de la libertad individual). Lo que sí explicó Kelsen, muy acertadamente por cierto, es que aparte del concepto específico de Estado de Derecho que hoy empleamos, existe también una noción muy amplia de Estado de Derecho, que obedece al hecho de que el Estado no tiene sustancia propia, no posee existencia pre-jurídica y se ha manifestado siempre a través de actos jurídicos. Esta distinción entre las nociones amplia y restringida de Estado de Derecho nos parece bastante clara y no vemos en ella confusión alguna ${ }^{48}$. Lo que sí parece subsistir es el intento de hacer de Kelsen y del positivismo jurídico en general -no nos cansaremos de insistir en ello- una caricatura deforme ${ }^{49}$.

Habiendo señalado lo anterior, nos parece que el positivismo jurídico al no entorpecer, sino facilitar, la identificación de nuestro objeto de estudio (el derecho positivo; aquél que supera el test de la regla de reconocimiento), también nos facilita, sin proponérselo quizás, nuestras tareas evaluativas y críticas, ya que muy difícilmente se puede valorar lo que no puede describirse bien. Y allí entra justamente el Estado de Derecho: esos principios y reglas cuyo propósito es asegurar cierta calidad del derecho, para que éste no sea producto de la arbitrariedad o el abuso por parte de quienes tienen la potestad de ejercer, como ultima ratio, la coacción estatal ${ }^{50}$.

\footnotetext{
47 Un ejemplo bastante claro y reciente de ese iusmoralismo en Alexy (2016).

48 Veamos la cita, in extenso: "Si se reconoce en el Estado un orden jurídico, todo Estado es un Estado de derecho, dado que esta expresión es pleonástica. En los hechos es empleada para designar cierto tipo de Estado, a saber aquel que corresponde a las exigencias de la democracia y de la seguridad jurídica. 'Estado de derecho', en este sentido específico, es un orden judicial y la administración está regida por leyes, es decir, por normas generales, dictadas por un parlamento elegido por el pueblo, con o sin participación de un jefe del Estado situado en la cúspide del gobierno, siendo los miembros del gobierno responsables de sus actos, los tribunales independientes y encontrándose garantizados ciertos derechos y libertades de los ciudadanos, en especial, la libertad de creencia y de conciencia y la libertad de expresión". Cfr. Kelsen (2002a: 315).

49 Ver también sobre este punto en específico: García Amado (2010: 389).

50 En la Filosofía del Derecho española destacan autores que han publicado extensamente sobre el Estado de Derecho, siendo el más importante de todos Díaz García (2010), quien en la década de 1960 inició el debate sobre cuáles elementos debía reunir el Estado de Derecho, según Díaz García (ibídem: 46): imperio de la ley, división de poderes, legalidad de la Administración, derechos y libertades fundamentales) y si el Estado Social y el Estado Democrático eran también manifestaciones del Estado de Derecho (a lo cual Díaz García da una respuesta afirmativa). Más recientemente, destacan los aportes de Hierro Sánchez-Pescador (1996 y 2001), así como de Laporta San Miguel (2007). Aun no siendo el
} 
Llegados a este punto, necesario es reconocer que el Estado de Derecho (llamado a veces Estado Liberal de Derecho) tiene, decirlo es casi obvio, enemigos en los oponentes al liberalismo político y económico, los cuales han influido decisivamente en la política de la postguerra y ello se manifiesta en los textos constitucionales producidos luego de 1945. Aparte de ello, diferentes calificativos se han sumado al Estado de Derecho, precisamente para reducirlo sustancialmente. Nos referimos a cláusulas constitucionales de la postguerra con las cuales se quiso "dejar atrás" el Estado de Derecho, para buscar otras cosas: (i) representación y participación popular en el sistema político (Estado Democrático de Derecho); (ii) un sistema de bienestar mediante la redistribución de la riqueza en apelación a la llamada "justicia social" (Estado Social de Derecho); y la absolutización moral del Estado (Estado de Derecho y de Justicia).

Si bien liberalismo y democracia pueden ser armonizados con algunas tensiones a través de límites constitucionales permanentes al poder circunstancial de las mayorías, mucho más difícil es controlar jurídicamente el igualitarismo material de la justicia social y del Estado Social o, ya imposible, ejercer ese control frente a la pretensión moralizante del Estado de Justicia ${ }^{51}$. El hecho de que estos contenidos hayan sido positivizados -puestos en las constituciones escritas, junto con una panoplia de dudosos derechos y vagos principios, tiene diversas interpretaciones por parte de los pensadores antipositivistas: (i) por una parte, los iusmoralistas y neoconstitucionalistas consideran que el positivismo jurídico ha sido "superado", especialmente en lo atinente a las pretensiones de certeza y previsibilidad, así como en lo referido a la posibilidad de describir el "edificio jurídico" sin hacer también una valoración del mismo; (ii) por otra parte, los autores liberales ven ratificadas sus aprehensiones hacia el positivismo, el cual, nuevamente ha convertido en "derecho" cualquier cosa que diga o mande el Estado, por arbitraria que sea. Conforme a estas interpretaciones, el Estado de Derecho, en cierta forma, habría sido una víctima más del positivismo jurídico.

Con relación a lo anterior, basta con ratificar que conforme a las tesis fuertes del positivismo jurídico, antes repasadas, ningún fundamento hallan estas interpretaciones. Muy por el contrario, una perspectiva externa como la defendida por los positivistas, lo que vendría a decirnos es que, sin lugar a dudas, los textos constitucionales contemporáneos -particularmente los de la Europa de postguerrano responden a la idea moderna de Estado de Derecho. Para llegar a tal conclusión, basta con comparar los textos constitucionales decimonónicos y los textos constitucionales vigentes en la actualidad. Por dar cuenta de esa realidad, no puede ser culpable el positivismo jurídico, sino la irrupción de determinadas ideas sobre la sociedad que han encontrado eco institucional.

Y en materia constitucional vemos una última amenaza al Estado de Derecho, que no siempre se desprende de la letra de las constituciones: la burocratización del poder público en lo que hoy es conocido en todo el mundo como Estado

objetivo particular de este trabajo analizar estas discusiones específicamente en el contexto español, podemos decir que desde la Constitución de 1978 la corriente del debate se mueve en el sentido de ampliar la noción liberal de Estado de Derecho, para incluir cuestiones distintas a los límites que debe tener la autoridad estatal para no ejercer arbitrariamente sus poderes en detrimento de la libertad individual. A eso apunta precisamente Hierro Sánchez-Pescador (1996: 288-291), cuando aboga por una definición más amplia y ambiciosa de Estado de Derecho, mientras Laporta San Miguel (2017: 246-247) se centra, al igual que nosotros, en la idea de imperio de la ley, o rule of law.

${ }^{51}$ El Estado de Justicia es una noción de inspiración claramente antiliberal, muy identificada con el fascismo (Del Vecchio, Gentile), que ve en la justicia el fundamento del Estado. Así, el Estado y sus funcionarios se entienden moralmente superiores a las personas, sujetos egoístas "y con tendencia al atomismo social". Cfr. Sampay (1942: 289-298). 
Administrativo ${ }^{52}$, que ha venido a reeditar las antiguas prerrogativas medievales contra las cuales irrumpió el constitucionalismo y la idea de Estado de Derecho- y las ha puesto en cabeza, no ya de un monarca absoluto, sino de una pléyade de funcionarios públicos ${ }^{53}$.

La característica esencial de este Estado Administrativo, cuya versión juridificada es la del Derecho Administrativo, es que como producto de una legislación absolutamente desbordada, orientada primordialmente por las promesas irresponsables de los políticos hacia la sociedad, dicha legislación no hace otra cosa sino delegar un conjunto de atribuciones a la rama ejecutiva, cuyo tamaño, en términos de órganos y entes, funcionarios y recursos materiales, no hace sino crecer. Dichas atribuciones quiebran completamente el principio de legalidad y la separación de poderes del Estado de Derecho, pues incluyen: (i) amplias facultades normativas -o "reglamentarias"- para sujetos que no son representantes de la población; (ii) facultades propiamente coactivas o ejecutivas -con potestad de autotutela o, lo que es igual, sin necesidad de pase judicial-; y (iii) facultades "cuasijurisdiccionales" rectius: la potestad de dirimir controversias, incluso entre particulares, sin las garantías del debido proceso judicial-.

La tendencia creciente de este poder en manos de la burocracia se debe más a una deficiente práctica institucional ${ }^{54}$, que a una variación sustancial de los textos constitucionales y se ha visto por igual en los distintos sistemas jurídicos ${ }^{55}$.

52 Bajo la Constitución de Weimar, Schmitt (2006: 66-84) advertía que la Administración (el Estado Administrativo, dicho por él mismo) se había convertido en un legislador extraordinario y que sus medidas estaban suplantando a la ley propia del Estado legislativo parlamentario.

${ }^{53}$ Ello se debe, sin lugar a dudas, a la continuidad histórica -y no de ruptura, como suele pensarse- en las ideas que sobre el fenómeno burocrático se da entre el Antiguo Régimen y la Revolución Francesa. Nadie ha expresado esta tesis sobre la continuidad histórica mejor que Tocqueville: "Es imposible leer la correspondencia de un intendente del antiguo régimen con sus superiores y sus subordinados, sin admirar hasta qué punto la semejanza de las instituciones hacía que los funcionarios administrativos de aquella época se pareciesen tanto a los nuestros. Parece que se dan la mano a través del abismo de la revolución que los separa. Otro tanto puede decirse de los administrados. Nunca se ha puesto mejor de manifiesto el poder de la legislación sobre el espíritu de los hombres". Cfr. Tocqueville (2012: 93). "Los funcionarios administrativos -burgueses casi todos- forman ya una clase con un espíritu particular, sus tradiciones, sus virtudes, su honor, su orgullo. Es la aristocracia de la nueva sociedad, ya formada y viva, que sólo espera que la Revolución le haga un sitio". Cfr. Tocqueville (ibídem: 95). La posición de Tocqueville es acompañada, con matices, por García de Enterría (1994: 51-73).

54 Hierro Sánchez-Pescador (1996) se refiere críticamente al derecho producido en el seno de un mecanismo de integración regional, como la Unión Europea, el cual no emana de legislador alguno, sino de órganos burocráticos no representativos.

${ }^{55}$ Este fenómeno se denunció originalmente en Inglaterra como un quebrantamiento del rule of law (por el contrario, en Francia, Prusia y el resto de Europa Continental esta forma de despotismo burocrático formaba parte de su cultura tradicional). Así, Dicey (1992: 213-267) siempre rechazó a finales del siglo $\mathrm{XIX}$ la posible influencia del régimen administrativo francés en el constitucionalismo británico. Asimismo, Lord Hewart (1975) denunció la ya notable presencia de dicho fenómeno en la Inglaterra de comienzos del siglo $\mathrm{XX}$, en un enjundioso análisis legal y jurisprudencial donde se mostraba cómo la soberanía parlamentaria estaba dando paso a la "legislación ministerial", en detrimento del rule of law. En Estados Unidos el debate está apenas abierto, con autores claramente favorables al Administrative State, tales como Jerry Mashaw, Cass Sunstein, Daniel R. Ernst y Adrian Vermeule, por una parte, y una ruidosa minoría liberal encabezada por Richard Epstein y Philip Hamburger, por otra parte, siendo estos últimos quienes niegan absolutamente la compatibilidad entre dicho Administrative State y la Constitución americana. Como muestras de este debate aún en curso, recomendamos ver las obras siguientes que figuran en la bibliografía del presente trabajo: (i) Mashaw (2012); (ii) Ernst (2014); (iii) Sunstein y Vermeule (2015); (iv) Epstein (2013); (v) Hamburger (2014); (vi) Lawson, (2015); y (vii) Vermeule (2016). Por su parte, García de Enterría (1998: 165-210), también para el caso de Estados Unidos, analiza el problema de la doctrina judicial de deferencia hacia la Administración en materia de interpretación de textos legales -incluso en lo relativo a su propia competencia- (en especial, la del famoso caso Chevron USA Inc. c. Natural Resources Defense Council Inc., de 25 de junio de 1984, decidido por la Corte Suprema de Justicia). 
¿Cómo pudo llegarse hasta esta situación de aparente vuelta al absolutismo? ¿Habrá sido como producto del positivismo jurídico? Muy difícilmente. Para criticar este estado de cosas, antes de negar el carácter de "derecho" a la legislación habría que analizar muy sesudamente cómo la política ha empleado instrumentalmente el sistema jurídico en cada caso concreto para pervertir el Estado de Derecho y, en tal labor, en muchas ocasiones criticada como una actitud "descriptivista", el positivismo jurídico resulta de lo más útil para registrar cómo se pervierten los principios de legalidad y de separación de poderes, para llegar al resultado constatable de afectar la libertad de las personas.

Por nuestra parte, creemos que puede realizarse buena legislación, consistente en reglas verdaderamente generales y abstractas, que permitan la coordinación de los individuos en la realización de sus respectivos proyectos de vida. Asimismo, creemos que la Legislación sirve como constatación del grado de respaldo institucional que tiene un derecho que va creciendo de forma evolutiva y espontánea, así como para ordenar y actualizar el material normativo disperso. No creemos en el derecho como mandatos -tal y como tampoco lo hace el positivismo de H.L.A. Hart, con su revisión y crítica de la teoría imperativa de Austin y otros utilitaristas ${ }^{56}$ y sí creemos que los límites y parámetros para hacer un derecho de calidad-como los propugnados por el Estado de Derecho- deben ser el resultado de un consenso de la sociedad, el cual se vea reflejado en el derecho positivo. Así es cómo, a fin de cuentas, el positivismo se convierte en un aliado del Estado de Derecho y no en su enemigo, como erróneamente se afirma. Si, además, el Estado de Derecho es el aliado esencial de la libertad individual, el positivismo no sólo no es enemigo de la libertad individual, como también se asevera de forma equivocada, sino que resulta perfectamente compatible con aquella.

\section{Algunas conclusiones}

7.1.- Es hora de superar la caricatura deformante que se ha hecho del positivismo jurídico y centrarse en las tesis fuertes de este, vale decir, la separación conceptual entre derecho y moral, y las fuentes sociales del derecho. El positivismo jurídico no es una doctrina acerca de la justificación de cualquier orden jurídico-político, ni es responsable de que hayan existido -y existan- dictaduras autoritarias o totalitarias.

7.2.- La separación conceptual entre derecho y moral, aparte de encontrar pleno asidero filosófico y teórico, permite realizar una necesaria y acertada tarea descriptiva de los sistemas jurídicos, para luego evaluar dichos sistemas, especialmente para ver si cumplen no solo con determinados principios y valores morales, sino también con otros ideales regulativos (tal y como ocurre con el del Estado de Derecho). Lo que debe quedar claro de esta tesis positivista es que -por razones lógicas- describir viene primero y evaluar viene después.

7.3.- La tesis de las fuentes sociales del derecho enfatiza el carácter instrumental y convencional de las normas jurídicas, las cuales deben su existencia, vigencia, validez y aplicabilidad a comportamientos que pueden ser descritos desde la perspectiva de un observador. La mejor explicación de esta realidad, sin lugar a dudas, es la proporcionada por H.L.A. Hart en su teoría de la regla de reconocimiento, la cual aclara definitivamente el objeto de los estudiosos del derecho.

7.4.- Ciertas propuestas filosóficas y teóricas, tales como las provenientes de la hermenéutica jurídica, el neoconstitucionalismo, los distintos iusmoralismos o el derecho como argumentación, suelen errar en el blanco en sus críticas

\footnotetext{
${ }^{56}$ Cfr. Arias Castillo (2013: 9 y ss.).
} 
antipositivistas. Las tareas descriptivas del positivismo jurídico no guardan relación con la defensa del rol político de los tribunales constitucionales o con la agenda de la justicia social y, por ende, el positivismo mal podría ser criticado por no defender dichas agendas.

7.5.- Tampoco encuentran asidero las críticas liberales al positivismo jurídico, especialmente aquéllas que van dirigidas a señalarlo como responsable de una identificación entre derecho y legislación, ahora que la legislación es tan numerosa e invasiva de la libertad individual. Aquí contrastan dos actitudes: la actitud del liberalismo de negar carácter jurídico a dichas invasiones a la libertad y la actitud del positivismo, que se limita a describir lo que ocurre con el surgimiento de dicha legislación y su reconocimiento por la sociedad. Esa legislación contemporánea es, en efecto, nociva para la libertad individual, pero no por ello la sociedad le ha negado la condición de derecho. El liberalismo, en todo caso, en vez de atacar al positivismo jurídico, debe ganar la batalla de las ideas, de la política y de la opinión pública, para que haya otro tipo de legislación más favorable a la libertad individual.

7.6.- El Estado de Derecho plasma el ideal regulativo del pensamiento liberal: una organización política racional, limitada en sus cometidos y sometida a reglas generales y abstractas. El positivismo jurídico no es un enemigo de dicho ideal, sino todo lo contrario. Por su claridad conceptual y expositiva, el positivismo jurídico es un aliado del Estado de Derecho y, por ende, de la libertad individual. La verdadera amenaza al Estado de Derecho proviene de su debilitamiento constitucional, debido a la existencia de cláusulas tales como las de Estado Social o Estado de Justicia, así como por la práctica relativamente reciente del Estado Administrativo.

7.7.- Es un reto para los interesados en mejorar no solo la eficacia de los sistemas jurídicos sino también la calidad de éstos, comprender y aprovechar el enfoque descriptivo del derecho, que siempre ha de acompañarse a su vez de un tratamiento analítico de aquél, pues gracias a la combinación de ambas aproximaciones a nuestro objeto de estudio es que puede lograrse un conocimiento real, verificable y útil del tipo de derecho practicado en cada sociedad. Rechazar tal propuesta, que es la formulada en este trabajo, implica allanar el camino a un objetivismo moral estatista, fomentar un liberalismo impracticable en las sociedades actuales o resignarse por déficit en el plano teórico ante el desbordamiento de una Administración más interventora y poderosa, que afecta el funcionamiento del derecho y reduce sustancialmente el ámbito de la libertad.

\section{Bibliografía}

ALEXY, R. (2016), La doble naturaleza del derecho, Trotta, Madrid.

ARIAS CASTILLO, T. A. (2007), "El último argumento de Ronald Dworkin en su disputa con H.L.A. Hart", Revista de Derecho del Tribunal Supremo de Justicia, núm. 24, pp. 39-61.

ARIAS CASTILLO, T. A. (2013), "Positivismo jurídico, estado de derecho y libertad". En HERRERA ORELLANA, L. A. (coord.), Enfoques sobre derecho y libertad en Venezuela, Academia de Ciencias Políticas y Sociales, Caracas, pp. 3-20.

ATIENZA RODRÍGUEZ, M. (2012), El derecho como argumentación, Ariel, Barcelona. ATIENZA RODRÍGUEZ, M. (2017), Filosofía del derecho y transformación social, Trotta, Madrid.

ATIENZA RODRÍGUEZ, M. y RUIZ MANERO, J. (2007), "Dejemos atrás el positivismo jurídico", Isonomía, núm. 27, pp. 7-28.

BARBERIS, M. (2003), "Neoconstitucionalismo, democracia e imperialismo de la moral". En CARBONELL SÁNCHEZ, M., Neoconstitucionalismo(s), Trotta, Madrid, pp. 259-278. 
BOBBIO, N. (2001), "Positivismo jurídico". En BOBBIO, N., El problema del positivismo jurídico, $7^{\text {a }}$ ed., Fontamara, México, pp. 37-66.

BOBBIO, N. (2015), Iusnaturalismo y positivismo jurídico, Trotta, Madrid.

CERRONI, U. (1976), Marx y el derecho moderno, Grijalbo, México.

COLEMAN, J. (Ed.) (2005), Hart's postscript. Essays on the Postscript to the Concept of Law, Oxford University Press, Oxford.

DÍAZ GARCÍA, E. (2010), Estado de derecho y sociedad democrática, Taurus, Madrid.

DICEY, A. V. (1992), Introduction to the study of the law of the constitution, Liberty Fund, Indianapolis.

DWORKIN, R. (2007), "El postscript de Hart y el sentido de la filosofía política". En DWORKIN, R., La justicia con toga, Marcial Pons, Madrid, pp. 159-204.

DWORKIN, R. (1999), Los derechos en serio, $4^{\mathrm{a}}$ reimp., Ariel, Barcelona.

EPSTEIN, R. (2013), "The perilous position of the rule of law and the administrative state", Harvard Journal of Law \& Public Policy, núm. 36, pp. 5-19.

ERSNT, D. R (2014), Tocqueville's Nightmare. The administrative state emerges in America, 1900-1940, Oxford University Press, New York.

FEHER, E. L. (2013), "Hans Kelsen frente al régimen nazi", Revista de la Facultad de Derecho de México, vol. 63, núm. 259, pp. 181-198.

FIGUEROA RUBIO, S. (Ed.) (2014), Hart en la teoría del derecho contemporánea. A 50 años de El Concepto de Derecho, Universidad Diego Portales, Santiago de Chile.

FISCHER, Á. (2017), De naturaleza liberal. Cómo la moral y el comportamiento humano tienen su mejor expresión en una sociedad liberal moderna, Catalonia, Santiago de Chile.

GARCÍA AMADO, J. A. (2003), "Filosofía hermenéutica y derecho". En GARCÍA AMADO, J. A., Ensayos de filosofía jurídica, Temis, Bogotá, pp. 219-240.

GARCÍA AMADO, J. A. (2010), “ ¿Es posible ser antikelseniano sin mentir sobre Kelsen?". En GARCÍA AMADO, J. A., El derecho y sus circunstancias. Nuevos ensayos de filosofía jurídica, Universidad Externado de Colombia, Bogotá, pp. 385-441.

GARCÍA AMADO, J. A. (2014), Positivismo jurídico, disponible en la siguiente dirección electrónica: https://goo.gl/qYcL9U (fecha de consulta: 28 de junio de 2018).

GARCÍA AMADO, J. A. (2015), Iusmoralismo(s). Dworkin/Alexy/Nino, Cevallos, Quito.

GARCÍA DE ENTERRÍA, E. (1994), Revolución francesa y administración contemporánea, Cívitas, Madrid.

GARCÍA DE ENTERRÍA, E. (1998), Democracia, jueces y control de la administración, Civitas, Madrid.

GARCÍA DE ENTERRÍA, E. (2000), Justicia y seguridad jurídica en un mundo de leyes desbocadas, reimp., Cívitas, Madrid.

GARCÍA-SALMONES ROVIRA, M. (2013), The project of positivism in international law, Oxford University Press, Oxford.

GUASTINI, R. (2014), "Releyendo a Hart". En FIGUEROA RUBIO, S. (Ed.), Hart en la teoría del derecho contemporánea. A 50 años de El Concepto de Derecho, Universidad Diego Portales, Santiago de Chile, pp. 61-76.

HAMBURGER, P. (2014), Is administrative law unlawful?, The University of Chicago Press, Chicago.

HART, H. L. A. (1962), "El positivismo jurídico y la separación entre el derecho y la moral". En HART, H. L. A., Derecho y moral. Contribuciones a su análisis, Depalma, Buenos Aires, pp. 1-64.

HART, H. L. A. (2006), Derecho, libertad y moralidad, Dykinson, Madrid.

HART, H. L. A. (2012), El concepto de derecho, $3^{a}$ reimp., Abeledo Perrot, Buenos Aires.

HAYEK, F. A. (2006), Derecho, legislación y libertad, Unión, Madrid.

HERRÁN ALONSO, J. C. (2010), El orden jurídico de la libertad. La aportación de F.A. 
Hayek al estudio del derecho, Unión, Madrid.

HERRERA ORELLANA, L. A. (2013), "Leyes, mandatos y regulación administrativa". En HERRERA ORELLANA, L. A. (coord.), Enfoques sobre derecho y libertad en Venezuela, Academia de Ciencias Políticas y Sociales, Caracas, pp. 333-374.

HEWART, G. (1975), The new despotism, reimp., Greenwood Press, Westport.

HIERRO SÁNCHEZ-PESCADOR, L. (1996), "El imperio de la ley y la crisis de la ley", DOXA, núm. 19, pp. 287-308.

HIERRO SÁNCHEZ-PESCADOR, L. (2001), Estado de derecho. Problemas actuales, Fontamara, México.

HIMMA, K. E. (2002), "Inclusive legal positivism". En: COLEMAN, J. y SHAPIRO, S. (Ed.), The oxford handbook of jurisprudence \& philosophy of law, Oxford University Press, Oxford, pp. 125-165.

HOERSTER, N. (2000), En defensa del positivismo jurídico, Gedisa, Barcelona.

HUNT, L. (2009), La invención de los derechos humanos, Tusquets, Barcelona.

KEARNS GOODWIN, D. (2006), Team of rivals: the political genius of Abraham Lincoln, Simon and Schuster, New York.

KELSEN, H. (1997), El estado como integración. Una controversia de principio, Tecnos, Madrid.

KELSEN, H. (2002a), Teoría pura del derecho, Porrúa, México.

KELSEN, H. (2002b), ¿Quién debe ser el defensor de la constitución?, reimp., Tecnos, Madrid.

KRAMER, M. H, GRANT, C., COLBURN, B. y HATZISTAVROU, I. (2012), El legado de H.L.A. Hart. Filosofía, política y moral, Marcial Pons, Madrid

LACEY, N. (2004), A life of H.L.A. Hart. The nightmare and the noble dream, Oxford University Press, Oxford.

LAPORTA SAN MIGUEL, F. J. (2007), El imperio de la ley. Una visión actual, Trotta, Madrid.

LAWSON, G. (2015), "The return of the King: The unsavory origins of administrative law", Texas Law Review, Vol. 93, pp. 1521-1545.

MARMOR, A. (2002). "Exclusive legal positivism". En: COLEMAN, J. y SHAPIRO, S. (Ed.), The oxford handbook of jurisprudence \& philosophy of law, Oxford University Press, Oxford, pp. 104-124.

MARTÍNEZ MESEGUER, C. (2009), La teoría evolutiva de las instituciones. La perspectiva austriaca, Unión, Madrid.

MASHAW, J. (2012), Creating the administrative constitution. The lost one hundred years of American administrative law, Yale University Press, New Haven.

MILLALEO HERNÁNDEZ, S. (2014), "El punto de vista interno de H. L. A. Hart (y Peter Winch): giros, comunidades y pluralidades". En FIGUEROA RUBIO, S. (Ed.), Hart en la teoría del derecho contemporánea. A 50 años de El Concepto de Derecho, Universidad Diego Portales, Santiago de Chile, pp. 143-180.

MONTOYA, J. y GONZÁLEZ ALTABLE, P. (1993), "Estado, derecho y libertad según F.A. Hayek", Anuario de filosofía del derecho, núm. 10, pp. 13-31.

MORALES LUNA, F. F. (2013), La filosofía del derecho de Uberto Scarpelli. Análisis del lenguaje normativo y positivismo jurídico, Marcial Pons, Madrid.

NOVOA MONREAL, E. (1981), El derecho como obstáculo al cambio social, $5^{\mathrm{a}}$ ed., Siglo Veintiuno, México.

ORUNESU, C. (2012), Positivismo jurídico y sistemas constitucionales, Marcial Pons, Madrid.

PAŜUKANIS, E. B. (1976), La teoría general del derecho y el marxismo, Grijalbo, México.

PEREIRA MENAUT, A. C. (2003), Rule of law o estado de derecho, Marcial Pons, Barcelona.

PERRY, S. R. (2001), "Hart's methodological positivism". En COLEMAN, J. (Ed.), Hart's postscript. Essays on the postscript to The Concept of Law, Oxford University Press, Oxford, pp. 311-354. 
POSNER, R. A. (2016), Divergent paths. The academy and the judiciary, Harvard University Press, Cambridge.

POZZOLO, S. (2003), "Un constitucionalismo ambiguo". En: CARBONELL SÁNCHEZ, M., Neoconstitucionalismo(s), Trotta, Madrid, pp. 187-210.

RODRÍGUEZ, C. (2002), "Teoría del derecho y decisión judicial. En torno al debate entre H.L.A. Hart y Ronald Dworkin". En RODRÍGUEZ, C. (Comp.), La decisión Judicial. El debate Hart - Dworkin, $4^{\text {a }}$ reimp., Siglo del Hombre, Bogotá, pp. 1588.

ROJAS, R. M. (2018), Fundamentos praxeológicos del derecho, Unión, Madrid.

RÜTHERS, B. (2016), Derecho degenerado. Teoría jurídica y juristas de cámara en el Tercer Reich, Marcial Pons, Madrid.

SAMPAY, A. E. (1942), La crisis del estado de derecho liberal-burgués, Losada, Buenos Aires.

SANTANATOGLIA, E. M. (2008), "La teoría jurídica de Friedrich A. von Hayek. Sus antecedentes y aportes epistemológicos a la teoría jurídica", Revista de análisis institucional, núm. 2, pp. 113-187.

SCARPELLI, U. (1997), Cos'è il positivismo giuridico, Edizioni Scientifiche Italiane, Nápoles.

SCHMITT, C. (2006), Legalidad y legitimidad, Comares, Granada.

SERNA BERMÚDEZ, P. (2005), "Hermenéutica y relativismo. Una aproximación desde el pensamiento de Arthur Kaufmann". En SERNA BERMÚDEZ, P. (Dir.), De la argumentación jurídica a la hermenéutica, Comares, Granada, pp. 279-316.

SQUELLA NARDUCCI, A. (2014), "El Concepto de Derecho puesto en un determinado contexto". En FIGUEROA RUBIO, S. (Ed.), Hart en la teoría del derecho contemporánea. A 50 años de El Concepto de Derecho, Universidad Diego Portales, Santiago de Chile, pp. 79-93.

SOSA WAGNER, F. (2005), Maestros alemanes del derecho público, $2^{\mathrm{a}}$ ed., Marcial Pons, Madrid.

SUNSTEIN, C. y VERMEULE, A. (2015), "Libertarian administrative law", University of Chicago Law Review, núm. 82, pp. 393-474.

STUČKA, P. I. (1974), La función revolucionaria del derecho y del estado, $2^{\mathrm{a}}$ ed., Península, Barcelona.

TINDALE, C. W. (2007), Fallacies and argument appraisal, Cambridge University Press, Cambridge.

TOCQUEVILLE, A. (2012), El antiguo régimen y la revolución, reimp., Alianza, Madrid.

VARGAS LLOSA, M. (2018), La llamada de la tribu, Alfaguara, Barcelona.

VERMEULE, A. (2016), Law's abnegation. From Law's Empire to the administrative state. Harvard University Press, Cambridge.

VICIANO PASTOR, R. y MARTÍNEZ DALMAU, R. (2011), "EI nuevo constitucionalismo latinoamericano. Fundamentos para una construcción doctrinal", Revista General de Derecho Público Comparado, núm. 9, pp.1-24.

VIGO, R. L. (2006), "El anti-positivismo jurídico de Ronald Dworkin". En VIGO, R. L., Perspectivas iusfilosóficas contemporáneas, $2^{\mathrm{a}}$ ed., Abeledo-Perrot, Buenos Aires, pp. 167-208.

VON MISES, L. (2009), Socialismo. Análisis económico y sociológico, Unión, Madrid. WALUCHOW, W. (2007), Positivismo jurídico incluyente, Marcial Pons, Madrid. 